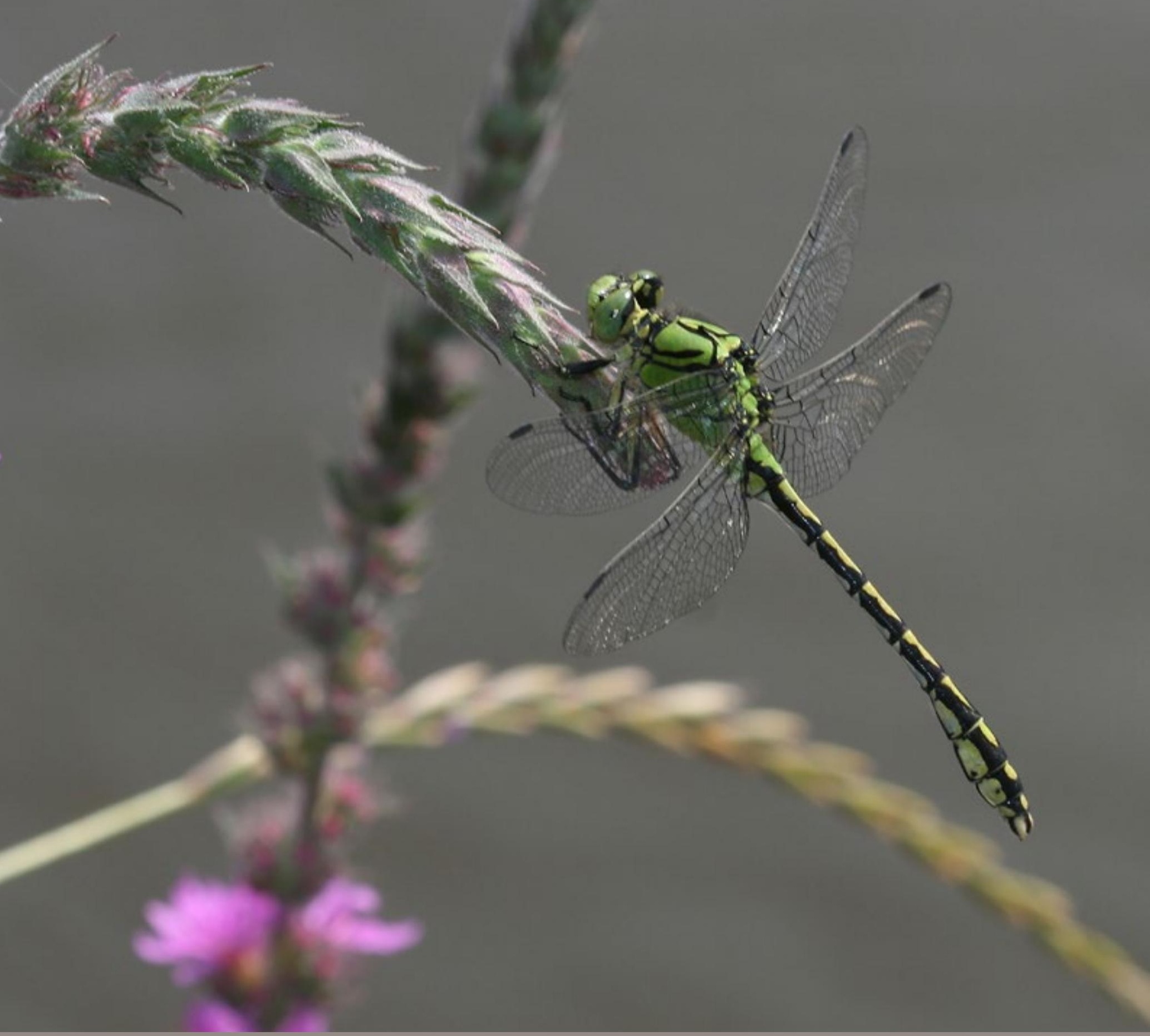

\title{
Habitatrichtlijnrapportage 2019: Annex B Habitatrichtlijnsoorten
}

Achtergronddocument 

Habitatrichtlijnrapportage 2019: Annex B Habitatrichtlijnsoorten 
Dit Technical report is gemaakt conform het Kwaliteitsmanagementsysteem (KMS) van de unit Wettelijke Onderzoekstaken Natuur \& Milieu, onderdeel van Wageningen University \& Research.

De WOT Natuur \& Milieu voert wettelijke onderzoekstaken uit op het beleidsterrein natuur en milieu. Deze taken worden uitgevoerd om een wettelijke verantwoordelijkheid van de Minister van Landbouw, Natuur en Voedselkwaliteit (LNV) te ondersteunen. We zorgen voor rapportages en data voor (inter)nationale verplichtingen op het gebied van agromilieu, biodiversiteit en bodeminformatie, en werken mee aan producten van het Planbureau voor de Leefomgeving zoals de Balans van de Leefomgeving.

\section{Disclaimer WOt-publicaties}

De reeks 'WOt-technical reports' bevat onderzoeksresultaten van projecten die kennisorganisaties voor de unit Wettelijke Onderzoekstaken Natuur \& Milieu hebben uitgevoerd.

WOt-technical report 170 is het resultaat van een onderzoeksopdracht van en gefinancierd door het ministerie van Landbouw, Natuur en Voedselkwaliteit (LNV). 


\section{Habitatrichtlijnrapportage 2019: Annex B Habitatrichtlijnsoorten}

Achtergronddocument

G.I. Bos-Groenendijk ${ }^{1}$ \& C.A.M van Swaay ${ }^{1}$

1 De Vlinderstichting

Projectnummer WOT-04-009-034.34

Wettelijke Onderzoekstaken Natuur \& Milieu

Wageningen, april 2020

Wot-technical report 170

ISSN 2352-2739

DOI $10.18174 / 514491$ 


\section{Referaat}

Bos-Groenendijk, G.I., C.A.M van Swaay (2020). Habitatrichtlijnrapportage 2019: Annex B Habitatrichtlijnsoorten; Achtergronddocument. Wettelijke Onderzoekstaken Natuur \& Milieu, WOttechnical report 170. 59 blz.; 0 fig.; 15 tab.; 4 ref; 2 Bijlagen.

Dit achtergronddocument beschrijft de totstandkoming van de rapportage van Annex B (soorten van de Habitatrichtlijn) over de periode 2013-2018, met data uit de periode 2012-2017. De rapportage wordt zes-jaarlijks uitgevoerd als verplichting onder de Europese Habitatrichtlijn (Artikel 17). Voor alle 81 Habitatrichtlijnsoorten (Annex II, IV en V) is de staat van instandhouding (SvI) vastgesteld volgens een door de Europese Commissie voorgeschreven beoordelingsmatrix. Het rapport beschrijft het rapportageproces en de onderbouwing van de keuzes die gemaakt zijn bij het invullen van de rapportageformats door de soortexperts. De SvI is per soort beoordeeld op de parameters: verspreidingsgebied, populatie, habitat en toekomstperspectief.

Trefwoorden: Habitatrichtlijn, Artikel 17, Annex B, verspreidingsgebied, populatie, habitat, toekomstperspectief, Staat van Instandhouding, Natura 2000

\section{Abstract}

Bos-Groenendijk, G.I., C.A.M van Swaay (2020). Habitats Directive Report 2019: Annex B Habitats Directive Species - Background Document. Statutory Research Tasks Unit for Nature \& the Environment, WOt Technical Report 170. 59 p.; 0 fig.; 15 tab.; 4 ref; 2 Appendices.

This background document explains the process of preparing the Annex B report (Habitats Directive species) for the reporting period 2013-2018, with data from the period 2012-2017. Article 17 of the EU Habitats Directive requires Member States to submit a progress report every six years. The conservation status of all 81 Habitats Directive species (Annex II, IV and V) has been established according to the evaluation matrix prescribed by the European Commission. The report describes the reporting process and explains the decisions made by the species experts when filling in the report formats. The conservation status of each species was assessed for the following parameters: range, population, habitat and future prospects.

Keywords: Habitats Directive, Article 17, Annex B, range, population, habitat, future prospects, conservation status, Natura 2000

Foto omslag: Tim Termaat

(C) 2020

\author{
Wageningen Environmental Research \\ Postbus 47, 6700 AA Wageningen \\ Tel: (0317) 480700 \\ e-mail: anne.schmidt@wur.nl
}

\author{
De Vlinderstichting \\ Postbus 506, 6700 AM Wageningen \\ Tel: (0317) 4673 46; \\ e-mail: info@vlinderstichting.nl
}

Wettelijke Onderzoekstaken Natuur \& Milieu (unit binnen de rechtspersoon Stichting Wageningen Research), Postbus 47, 6700 AA Wageningen, T 03174854 71, info.wnm@wur.nl, www.wur.nl/wotnatuurenmilieu.

WOT Natuur \& Milieu is onderdeel van Wageningen University \& Research.

Dit rapport is gratis te downloaden van https://doi.org/10.18174/514491 of op www.wur.nl/wotnatuurenmilieu. De WOT Natuur \& Milieu verstrekt geen gedrukte exemplaren van rapporten.

- Overname, verveelvoudiging of openbaarmaking van deze uitgave is toegestaan mits met duidelijke bronvermelding.

- Overname, verveelvoudiging of openbaarmaking is niet toegestaan voor commerciële doeleinden en/of geldelijk gewin.

- Overname, verveelvoudiging of openbaarmaking is niet toegestaan voor die gedeelten van deze uitgave waarvan duidelijk is dat de auteursrechten liggen bij derden en/of zijn voorbehouden. 


\section{Woord vooraf}

De Artikel 17-rapportage van de Habitatrichtlijnsoorten is geen gemakkelijke materie en een technische achtergrondrapportage geen ontspanningsliteratuur. Toch kan deze rapportage een waardevol naslagwerk worden voor wie zich in de materie wil verdiepen of voor wie bij de volgende rapportageronde betrokken raakt.

Veel dank zijn we verschuldigd aan de soortenexperts die de benodigde informatie hebben geleverd en veel geduld hebben getoond op de momenten dat alles niet in één keer gestroomlijnd liep. Ook danken we het projectteam en de begeleidingscommissie voor de prettige samenwerking en de constructieve feedback gedurende het proces.

Gerdien Bos \& Chris van Swaay

De Vlinderstichting 



\section{Inhoud}

$\begin{array}{ll}\text { Woord vooraf } & 5\end{array}$

$\begin{array}{lr}\text { Samenvatting } & 9\end{array}$

$\begin{array}{ll}\text { Summary } & 11\end{array}$

1

Inleiding

13

1.1 Aanleiding $\quad 13$

$\begin{array}{lll}1.2 & \text { Betrokkenen } & 13\end{array}$

$\begin{array}{lll}1.3 & \text { Proces } & 13\end{array}$

1.4 Inhoud van de rapportage $\quad 14$

$\begin{array}{lll}1.5 & \text { Leeswijzer } & 16\end{array}$

2

$\begin{array}{ll}\text { Methodiek en data Algemeen } & 17\end{array}$

$\begin{array}{lll}2.1 & \text { General information } & 17\end{array}$

$\begin{array}{lll}2.2 & \text { Annex V } & 17\end{array}$

$\begin{array}{lll}2.3 & \text { Biogeographical region } & 17\end{array}$

$\begin{array}{ll}2.4 & \text { Complementary information } \\ \end{array}$

$3 \quad$ Methodiek en data Range $r$

$\begin{array}{lll}3.1 & \text { Maps } & 19\end{array}$

3.1.1 Methode 19

$\begin{array}{ll}3.1 .2 \text { Technische specificaties } & 19\end{array}$

$\begin{array}{ll}3.1 .3 \text { Gevoelig voor verzamelen } & 20\end{array}$

$\begin{array}{ll}3.1 .4 \text { Herintroductie } & 20\end{array}$

3.2 Range 20

3.2.1 Oppervlakte en trend 20

3.2.2 Favourable Reference Range $\quad 21$

3.2.3 Verschil met vorige rapportage $\quad 21$

4 Methodiek en data Population $\quad 23$

4.1 Population $\quad 23$

4.1.1 Populatiegrootte $\quad 23$

$\begin{array}{ll}4.1 .2 \text { Trend } & 24\end{array}$

4.1.3 Favourable Reference Population $\quad 24$

4.1.4 Verschil met vorige rapportage $\quad 24$

$\begin{array}{lll}4.2 & \text { Natura } 2000 & 24\end{array}$

$5 \quad$ Methodiek en data Habitat, Pressures en Measures 25

$\begin{array}{lll}5.1 & \text { Habitat } & 25\end{array}$

$\begin{array}{lll}5.2 & \text { Pressures and Threats } & 25\end{array}$

$\begin{array}{lll}5.3 \text { Measures } & 26\end{array}$

$\begin{array}{llr}6 & \text { Methodiek en data Future Prospects } & 27\end{array}$

$\begin{array}{lll}6.1 & \text { Future prospects } & 27\end{array}$

$\begin{array}{llr}7 & \text { Methodiek en data Conclusions } & 29\end{array}$

$\begin{array}{llr}7.1 & \text { Conclusions } & 29\end{array}$ 
Verantwoording

33

Bijlage 1 Soortenlijst

Bijlage 2 Handleiding voor de Artikel 17 rapportage 2019 


\section{Samenvatting}

De Europese Lidstaten zijn verplicht op grond van artikel 17 van de Europese Habitatrichtlijn te rapporteren over de maatregelen die genomen zijn en over de mate van doelbereik. De rapportage wordt zes-jaarlijks uitgevoerd als verplichting onder de Europese Habitatrichtlijn (Artikel 17). In 2019 is gerapporteerd over de periode 2013-2018, met data uit 2012-2017. De soortrapportages zijn ingevuld door soortexperts van de verschillende soortenorganisaties. Voor alle 81 Habitatrichtlijnsoorten (Annex II, IV en V) is de staat van instandhouding (SvI) vastgesteld volgens een door de Europese Commissie voorgeschreven beoordelingsmatrix. De rapportage bestaat per soort uit een onderdeel met algemene informatie (inclusief een verspreidingskaart) en een onderdeel per biogeografische regio waarin de SvI is bepaald. De biogeografische regio's waarover Nederland heeft gerapporteerd zijn Marine Atlantic en Atlantic. Omdat geen van de soorten in beide regio's voorkomt, is per soort slechts voor één biogeografische regio gerapporteerd (trekvissen hoefden alleen in zoet water gerapporteerd te worden). De SVI is per soort beoordeeld op de parameters: verspreidingsgebied, populatie, habitat en toekomstperspectief. In deze technische achtergrondrapportage wordt beschreven welke methode daarbij is gehanteerd. Daardoor wordt inzichtelijk gemaakt op welke keuzes de rapportage is gebaseerd. Dit document is dan ook bedoeld als naslagwerk bij de inhoudelijke Artikel 17-rapportage van 2019 en bij het invullen van de rapportageformats in 2025 . 



\section{Summary}

Article 17 of the Habitats Directive requires the EU Member States to report on the measures they have taken and the progress made towards favourable conservation status. These reports must be prepared every six years. In 2019 the Dutch national report was submitted for the period 2013-2018, with data from 2012-2017. The species reports were compiled by species experts from the relevant species organisations. The conservation status of all 81 Habitats Directive species (Annex II, IV and V) was established according to the evaluation matrix prescribed by the European Commission. For each species the report contains a section with general information (including a range map) and a section in which the conservation status is determined for each biogeographical region. The biogeographical regions on which the Netherlands has reported are Marine Atlantic and Atlantic. Because none of the species is present in both regions, the report contains an assessment for just one biogeographical region for each species (migratory fish only have to be reported for freshwater habitats). The conservation status of each species was assessed for the following parameters: range, population, habitat and future prospects. This technical background document describes the methods used to make these assessments and explains the decisions made when compiling the report. This document is therefore intended as a reference work supporting the Article 17 report for 2019 and for the completion of the report formats in 2025. 



\section{$1 \quad$ Inleiding}

\section{$1.1 \quad$ Aanleiding}

De Europese Lidstaten zijn verplicht op grond van artikel 17 van de Europese Habitatrichtlijn te rapporteren over de maatregelen die genomen zijn en over de mate van doelbereik. Deze rapportage dient elke zes jaar gedaan te worden over de afgelopen periode. In 2019 is gerapporteerd over de periode 2013-2018. Het rapportageproces is eerder uitgebreid beschreven in Schmidt \& Adams (2015). In de huidige achtergrondrapportage wordt daarom alleen beknopt beschreven welke keuzes deze keer zijn gemaakt en welke zaken afweken van zes jaar geleden.

\subsection{Betrokkenen}

De soortrapportages zijn ingevuld door soortexperts van de verschillende soortenorganisaties. In tabel 1.1 is weergegeven welke soortexperts betrokken zijn geweest bij het invullen van de Annex Brapportage. In Bijlage 1 is nog eens per soort aangegeven welke soortexpert de betreffende soort heeft ingevuld. De zeezoogdieren zijn ingevuld door de Zoogdiervereniging en gecontroleerd door Wageningen Marine Research (WMR).

Tabel 1.1 Betrokkenen bij invullen Annex B-rapportage.

\begin{tabular}{lll} 
Betrokkene & Organisatie & Rol \\
Chris van Swaay & De Vlinderstichting & Coördinatie alle soorten \\
\hline Gerdien Bos & De Vlinderstichting & Coördinatie alle soorten \\
\hline Maurice LaHaye & Zoogdiervereniging & Zoogdieren \\
\hline Vilmar Dijkstra & Zoogdiervereniging & Zoogdieren \\
\hline Dick Bekker & Zoogdiervereniging & Zoogdieren \\
\hline Herman Limpens & Zoogdiervereniging & Vleermuizen \\
\hline Raymond Creemers & RAVON & Reptielen en amfibieën \\
\hline Jan Kranenbarg & RAVON & Vissen \\
\hline Erwin Winter & WMR & Trekvissen \\
\hline Irma Wynhoff & De Vlinderstichting & Dagvlinders \\
\hline Henk de Vries & De Vlinderstichting & Dagvlinders \\
\hline Jurriën van Deijk & De Vlinderstichting & Nachtvlinders \\
\hline Roy van Grunsven & De Vlinderstichting & Libellen \\
\hline Bram Koese & EIS Nederland & Overige ongewervelden \\
\hline John Smit & EIS Nederland & Overige ongewervelden \\
\hline Adriaan Gmelig Meyling & ANEMOON & Weekdieren \\
\hline Baudewijn Odé & FLORON & Vaatplanten \\
\hline Laurens Sparrius & BLWG & Mossen \& korstmossen \\
\hline
\end{tabular}

\subsection{Proces}

Hoewel de rapportageperiode officieel de jaren 2013-2018 beslaat, is er in 2019 gerapporteerd met data uit de periode 2012-2017. Het is onvermijdelijk dat de dataverwerking een jaar achter loopt, omdat het proces begin 2018 al gestart is. Data uit 2018 konden dus niet meegenomen worden in de rapportage van 2019. Dit is bij de vorige twee rapportages ook zo gedaan.

In het voorjaar van 2018 zijn de waarnemingen van 81 soorten (Bijlage 1) uit de periode 2012-2017 uit de NDFF gehaald. Op basis van deze dataset zijn verspreidingskaarten gemaakt. De kaarten zijn 
vervolgens gecontroleerd door de soortexperts en soms op basis van additionele data uit andere databases en/of expert judgement aangepast. Intussen werden de benodigde trends (Range en Population) berekend door het CBS.

Op dinsdag 11 september 2018 heeft er een workshop plaatsgevonden waarvoor alle soortexperts waren uitgenodigd (op twee na was iedereen aanwezig). De workshop duurde de hele dag en werd begeleid door Chris van Swaay en Gerdien Bos. 's Ochtends werd de methode voor het invullen uitgelegd en mocht iedereen zelf aan de slag met het invullen van een soort. Als leidraad voor het invullen hadden we een handleiding opgesteld op basis van de Guidelines die door de EU waren verstrekt (DG Environment 2017). De handleiding is opgenomen in Bijlage 2. 's Middags werden de aandachtspunten bediscussieerd en de rest van de middag kon besteed worden aan het verder invullen van de soorten. De workshop had tot doel dat iedereen zoveel mogelijk dezelfde methode zou volgen. Voor het invullen van de rapportageformats is gebruik gemaakt van de digitale invultool die beschikbaar werd gesteld door de EU (European Environment Agency 2018). In het najaar van 2018 zijn de rapportageformats verder ingevuld, gecontroleerd en verbeterd. In het voorjaar van 2019 zijn ze gecontroleerd en becommentarieerd door het ministerie van LNV (Annemiek Adams), waarna nog enkele aanpassingen zijn doorgevoerd. De rapportage is ingediend op 1 juli 2019 door LNV. Na opmerkingen vanuit het European Topic Centre zijn nog twee foutjes gecorrigeerd.

\subsection{Inhoud van de rapportage}

Het rapportageformat (European Environment Agency 2018) bestond uit twaalf onderdelen. De eerste drie onderdelen (general information, maps, information related to Annex $V$ species) dienden ingevuld te worden op nationaal niveau, de overige onderdelen op het niveau van de biogeografische regio (tabel 1.2). In de praktijk waren er geen soorten die voor meer dan één biogeografische regio ingevuld dienden te worden.

Tabel 1.2 Rapportage-onderdelen Annex B (HR-soorten).

\section{Rapportage-onderdelen}

\section{General information}

1.1 Member State

1.2 Species code

1.3 Species scientific name

1.4 Alternative species scientific name

1.5 Common name

1. 2. Maps

2.1 Sensitive species

2.2 Year or period

2.3 Distribution map

2.4 Method used

2.5 Additional map

\section{3. Information related to Annex $V$ species (Art. 14)}

3.1 Is the species taken in the wild/exploited?

3.2 Which of the measures in Art. 14 have been taken?

3.3 Hunting bag or quantity taken in the wild

3.4 Method used

3.5 Additional information

3. 4. Biogeographical and marine regions

4.1 Biogeographical or marine region where the species occurs

4.2 Sources of information

\section{Range}

5.1 Surface area

5.2 Short-term trend period

5.3 Short-term trend direction

5.4 Short-term trend magnitude 
5.5 Short-term trend method used

5.6 Long-term trend period

5.7 Long-term trend direction

5.8 Long-term trend magnitude

5.9 Long-term trend method used

5.10 Favourable reference range

5.11 Change and reason for change

5.12 Additional information

\section{Population}

6.1 Year of period

6.2 Population size

6.3 Type of estimation

6.4 Additional population size

6.5 Type of estimation

6.6 Method used population size

6.7 Short-term trend period

6.8 Short-term trend direction

6.9 Short-term trend magnitude

6.10 Short-term trend method used

6.11 Long-term trend period

6.12 Long-term trend direction

6.13 Long-term trend magnitude

6.14 Long-term trend method used

6.15 Favourable reference population

6.16 Change and reason for change

6.17 Additional information

7. Habitat for the species

7.1 Sufficiency of area and quality of occupied habitat

7.2 Method used

7.3 Short-term trend period

7.4 Short-term trend direction

7.5 Short-term trend method used

7.6 Long-term trend period

7.7 Long-term trend direction

7.8 Long-term trend method used

7.9 Additional information

\section{Main pressures and threats}

8.1 Characterisation of pressures and threats

8.2 Sources of information

8.3 Additional information

\section{Conservation measures}

9.1 Status of measures

9.2 Main purpose of the measures taken

9.3 Location of the measures

9.4 Response to the measures

9.5 List of main conservation measures

9.6 Additional information

\section{Future prospects}

10.1 Future prospects of parameters

10.2 Additional information

\section{Conclusions}

11.1 Range

11.2 Population

11.3 Habitat for the species

11.4 Future prospects 
11.6 Overall trend in conservation status

11.7 Change and reasons for change

11.8 Additional information

12 Natura 2000

12.1 Population size

12.2 Type of estimate

12.3 Method used

12.4 Short-term trend direction

12.5 Method used

12.6 Additional information

\section{Complementary information}

13.1 Justification of \% thresholds for trends

13.2 Trans-boundary assessment

13.3 Other relevant information

\subsection{Leeswijzer}

In de volgende hoofdstukken worden de rapportage-onderdelen besproken en wordt toegelicht welke keuzes zijn gemaakt bij het invullen van het format. In hoofdstuk 2 komen de algemene onderdelen 1 , 3, 4 en 13 aan bod. In hoofdstuk 3 wordt de methode van het onderdeel Range (verspreidingsgebied) (5) en de Maps (verspreidingskaarten) (2) besproken. Hoofdstuk 4 gaat in op het onderdeel Population (populatie) (6) inclusief de situatie in Natura 2000-gebieden (12) en hoofdstuk 5 op de Habitat (leefgebied) (7), inclusief de Pressures and Threats (drukfactoren en bedreigingen) en de Measures (maatregelen) ( $8 \& 9$ ). Hoofdstuk 6 bespreekt de methode van het onderdeel Future Prospects (toekomstperspectief) (10) en tenslotte wordt hoofdstuk 7 gewijd aan de Conclusion (conclusie) (onderdeel 11). 


\section{Methodiek en data Algemeen}

In het algemene deel is informatie opgenomen zoals codes voor de soort, het land en de biogeografische regio, soortnamen, literatuurbronnen, informatie over exploitatie (in geval van Annex $\mathrm{V}$ ) en andere relevante informatie die nergens anders aan bod is gekomen.

\subsection{General information}

Tabel 2.1 Beschrijving rapportage-onderdeel 1; algemene informatie.

Rapportage-onderdelen

\section{General information}

1.1 Member State

1.2 Species code

1.3 Species scientific name

1.4 Alternative species scientific name

1.5 Common name
Beschrijving

Lidstaatcode, in dit geval altijd NL

4-cijferige soortcode

Wetenschappelijke soortnaam

Alternatieve wetenschappelijke naam (optioneel)

Gangbare Nederlandse naam

Bij dit onderdeel zijn de soortcode, de wetenschappelijke naam en de Nederlandse naam ingevuld (tabel 2.1). De gebruikte namen en codes staan in Bijlage 1.

\subsection{Annex $\mathrm{V}$}

Tabel 2.2. Beschrijving rapportage-onderdeel 3; informatie gerelateerd aan Annex V soorten.

Rapportage-onderdelen

3. Information related to Annex $V$ species (Art. 14)

3.1 Is the species taken in the wild/exploited?

3.2 Which of the measures in Art. 14 have been taken?

3.3 Hunting bag or quantity taken in the wild

3.4 Method used

3.5 Additional information

\section{Beschrijving}

Is er sprake van exploitative?

Welke maatregelen worden genomen?

Hoeveel wordt er gevangen?

Op wat voor data is het invullen gebaseerd?

Ruimte voor toelichting

Voor de Annex V-soorten is ingevuld of de soorten verzameld, gevangen of bejaagd mogen worden, of ondanks een verbod in de praktijk toch verzameld, gevangen of bejaagd worden (tabel 2.2). Als het antwoord op vraag 3.1 NEE is, hoeven de rest van de vragen niet ingevuld te worden. Alleen voor barbeel en rivierprik geldt dat ze in een bepaalde periode van het jaar gevangen mogen worden. Omdat harde data ontbreken, is dit onderdeel voor deze twee soorten vooral ingevuld op basis van expert judgement.

\subsection{Biogeographical region}

Tabel 2.3 Beschrijving van rapportage-onderdeel 4; biogeografische en mariene regio's.

\section{Biogeographical and marine regions}

4.1 Biogeographical or marine region where the species occurs Biogeografische regio

Bronnen 
Alle Nederlandse soorten worden ingedeeld in de Atlantische regio (ATL) of de Marien Atalantische regio (MATL). In de laatste categorie vallen alleen de vier zeezoogdieren. De trekvissen, die zowel in de zoetwaterrivieren als in de zee voorkomen, hoefden slechts voor de Atlantische regio (dus het nietmariene deel) gerapporteerd te worden.

In veld 4.2 zijn alle bronnen opgenomen die als basis hebben gediend voor de rapportage. Dit betreffen zowel de databronnen (NDFF, NEM, etc.) als de literatuurbronnen met informatie (zoals beschermingsplannen, rapporten of artikelen) (tabel 2.3).

\subsection{Complementary information}

Tabel 2.4 Beschrijving van rapportage-onderdeel 13; aanvullende informatie.

\begin{tabular}{ll} 
Rapportage-onderdelen & Beschrijving \\
$\mathbf{1 3}$ Complementary information & \\
\hline 13.1 Justification of \% thresholds for trends & Alleen als bij 11 een lagere drempelwaarde is gebruikt \\
\hline 13.2 Trans-boundary assessment & Alleen als twee lidstaten gezamenlijk rapporteren \\
\hline 13.3 Other relevant information & Ruimte voor additionele informatie \\
\hline
\end{tabular}

In dit onderdeel was ruimte voor informatie die nog nergens anders een plek had gekregen, maar die toch nog relevant was (tabel 2.4). Hier is in zeer beperkte mate gebruik van gemaakt. De vragen 13.1 en 13.2 waren voor geen van de soorten van toepassing. 


\section{Methodiek en data Range}

Het onderdeel over de Range bestaat uit de twee onderdelen Maps (verspreidingskaarten) en Range (verspreidingsgebied) (tabel 3.1 en 3.2). In dit hoofdstuk wordt besproken hoe de verspreidingskaarten tot stand zijn gekomen en hoe ze als basis zijn gebruikt voor het invullen van de informatie over het verspreidingsgebied.

\subsection{Maps}

Tabel 3.1 Beschrijving rapportage-onderdeel 2; verspreidingskaarten.

\begin{tabular}{ll} 
Rapportage-onderdelen & Beschrijving \\
\hline 2. Maps & Geef aan of de soort gevoelig is voor verzamelen \\
\hline 2.2 Year or period & Periode van de verspreidingsdata op de kaart \\
\hline 2.3 Distribution map & Klik aan als er een kaart wordt bijgevoegd \\
\hline 2.4 Method used & Kies de methode waarop de kaart is gebaseerd \\
\hline 2.5 Additional map & Ruimte voor een extra kaart (optioneel) \\
\hline
\end{tabular}

\subsubsection{Methode}

Voor alle soorten is een verspreidingskaart gemaakt met data uit de periode 2012-2017. Als basis voor de kaarten is eerst een dataset uit de NDFF gebruikt. De kaarten zijn vervolgens gecontroleerd door de soortexperts. Zij hebben gecontroleerd:

1. Of alle hokken daadwerkelijk een beeld geven van het actueel voorkomen van de soort (zwervers zijn uit de dataset verwijderd).

2. Of het verspreidingsbeeld compleet is. Dit bleek niet voor alle soorten het geval te zijn. Voor enkele soorten zijn additionele datasets aangeleverd omdat deze nog niet naar de NDFF waren geüpload (nauwe korfslak, zeggekorfslak, platte schijfhoren, medicinale bloedzuiger en brede geelgerande waterroofkever).

Voor de gebruikte methode kon gekozen worden uit vier opties:

a. Complete survey or statistically robust estimate

b. Based mainly on extrapolation from a limited amount of data

c. Based mainly on expert opinion with very limited data

d. Insufficient or no data available

In de meeste gevallen is gekozen voor methode a. Dit was het geval wanneer de data uit de NDFF (eventueel aangevuld met andere datasets) een vrij compleet beeld gaven en er slechts kleine aanpassingen nodig waren. Voor enkele soorten bleek de NDFF geen compleet beeld van de verspreiding te geven. Voor deze soorten zijn de kaarten handmatig door de experts aangevuld door de betreffende $10 \times 10$ km-hokken bij te kleuren. Dit geldt voornamelijk voor de vleermuissoorten, de trekvissen en de zeezoogdieren. Afhankelijk van hoeveel er is bijgeschat, is gekozen voor methode b of c. Er was voor geen van de soorten sprake van onvoldoende data, dus methode d is niet gekozen. Er zijn geen additionele kaarten toegevoegd.

\subsubsection{Technische specificaties}

De verspreidingskaarten zijn gemaakt in ETRS-projectie, zoals voorgeschreven door de Europese Commissie. Er is gebruik gemaakt van de shape-file die aangeboden werd op het Reference Portal van de EU (European Environment Agency 2018). Voor de begrenzing van Nederland moesten echter nog wel enkele zeedelen van België en Groot-Brittanië van de shape afgeknipt worden. 
Voor het bepalen van de range is gebruik gemaakt van de range-tool die eveneens aangeboden werd op het referentieportaal. De range-tool legt als het ware een envelop om de huidige verspreiding heen. Gaten in de verspreiding worden zo automatisch opgevuld. Omdat Nederland een relatief klein en goed onderzocht land is, hebben we ervoor gekozen om een 'gap distance' van 10 km (dus één hok) aan te houden.

\subsubsection{Gevoelig voor verzamelen}

De achtergrond van vraag 2.1 is dat wanneer een soort gevoelig is voor illegaal verzamelen, het mogelijk kwaad kan om de verspreidingskaart openbaar te maken. Omdat de kaarten echter gemaakt zijn op $10 \times 10 \mathrm{~km}$-schaal en ze dus voor verzamelaars geen gedetailleerde en nog niet algemeen bekende informatie geven over de plaats waar de soort voorkomt, is bij alle soorten gekozen voor NEE.

\subsubsection{Herintroductie}

Met betrekking tot (her)introductie zijn de volgende richtlijnen gehanteerd:

1. Uitgezette populaties binnen het natuurlijke historische verspreidingsgebied die zich minimaal vijf jaar zelfstandig hebben weten te handhaven tellen wel mee.

2. Uitgezette populaties buiten het natuurlijke historische verspreidingsgebied die zich minimaal honderd jaar zelfstandig hebben weten te handhaven tellen wel mee.

3. Uitgezette populaties buiten het natuurlijke historische verspreidingsgebied en jonger dan honderd jaar tellen niet mee.

4. Als onduidelijk is of een populatie is uitgezet of niet, telt hij wel mee.

\subsection{Range}

Tabel 3.2 Beschrijving rapportage-onderdeel 5; verspreidingsgebied.

\begin{tabular}{ll} 
Rapportage-onderdelen & Beschrijving \\
5. Range & Oppervlak van de huidige range in $\mathrm{km}^{2}$ \\
\hline 5.1 Surface area & 12 -jarige trendperiode \\
\hline 5.2 Short-term trend period & Richting van de trend \\
\hline 5.3 Short-term trend direction & Magnitude van de trend (optioneel) \\
\hline 5.4 Short-term trend magnitude & Methode waarmee de trend is berekend \\
\hline 5.5 Short-term trend method used & 24 jarige trendperiode (optioneel) \\
\hline 5.7 Long-term trend direction & Richting van de trend (optioneel) \\
\hline 5.8 Long-term trend magnitude & Magnitude van de trend (optioneel) \\
\hline 5.9 Long-term trend method used & Methode waarmee de trend is berekend (optioneel) \\
\hline 5.10 Favourable reference range & Huidige range t.o.v. Favourable Reference Range \\
\hline 5.11 Change and reason for change & Verschil met vorige rapportage \\
\hline 5.12 Additional information & Ruimte voor toelichting \\
\hline
\end{tabular}

\subsubsection{Oppervlakte en trend}

Het oppervlak van de huidige range is berekend met behulp van de range-tool: het aantal 10x10hokken van de range op de verspreidingskaart, vermenigvuldigd met 100 , is ingevuld bij onderdeel 5.1 .

De verspreidingstrend (op een schaal van 10x10 km-hokken) voor de periode 2006-2017 (short-term trend) is voor zover mogelijk berekend door het CBS. Bij de soorten waarvoor dit mogelijk was, is bij methode gekozen voor Complete survey or statistically robust estimate. Voor sommige soorten was niet voldoende data beschikbaar om een verspreidingstrend te berekenen. Voor die soorten is met behulp van een $\mathrm{Chi}^{2}$-test bepaald of er een significante trend is tussen de twee voorgaande rapportages en de huidige. In dat geval is bij methode gekozen voor Based mainly on extrapolation 
from a limited amount of data. Was dit ook niet mogelijk, dan is de trend ingeschat door de expert (Based mainly on expert opinion with very limited data) of is gekozen voor onbekend (Insufficient or no data available). De herkomst van de trend is toegelicht bij onderdeel 5.12. In een enkel geval is door de expert afgeweken van de trend die door het CBS is berekend. Ook dit is altijd toegelicht bij onderdeel 5.12 .

De optionele onderdelen 5.4, 5.6, 5.7, 5.8 en 5.9 zijn niet ingevuld.

\subsubsection{Favourable Reference Range}

Voor het invullen van onderdeel 5.10 is gekozen om te werken met operators $(\approx,>$ of $>>)$. Ingevuld moest worden of de FRR ongeveer gelijk is aan de huidige range, groter dan de huidige range of veel groter. De Favourable Reference Values zijn in 2014 opgesteld door Ottburg \& Van Swaay en deze waarden zijn dan ook als referentiewaarden gebruikt. Wanneer de huidige verspreiding groter is dan de FRR moest gekozen worden voor $\approx$ (< was bij verspreiding niet toegestaan volgens het format). Alleen bij de Brandt's vleermuis is gekozen voor 'onbekend'. Dit is toegelicht in veld 5.12.

\subsubsection{Verschil met vorige rapportage}

Bij onderdeel 5.11 is aangegeven of de oppervlakte van de huidige range verschilde van de oppervlakte van de range in de vorige rapportage. De reden van verandering is tevens aangegeven (werkelijke verandering, gebruik van een andere methode of toegenomen kennis) en toegelicht in veld 5.12. Er is gekozen voor werkelijke verandering wanneer er sprake was van een toenemende of dalende trend. Wanneer er ondanks een stabiele of onbekende trend toch verandering was ten opzichte van de vorige periode, is gekozen voor één van de andere redenen. 



\section{Methodiek en data Population}

De informatie over de populatiegrootte van soorten moest gegeven worden op twee schaalniveaus: op het niveau van heel Nederland voor alle soorten en op het niveau van het Natura 2000-netwerk voor de soorten van Annex II (tabel 4.1 en 4.2).

\subsection{Population}

Tabel 4.1 Beschrijving rapportage-onderdeel 6; populatie.

\begin{tabular}{ll}
$\begin{array}{l}\text { Rapportage-onderdelen } \\
\text { 6. Population }\end{array}$ & Beschrijving \\
\hline 6.1 Year of period & Periode waarin de data voor populatiegrootte is verzameld \\
\hline 6.2 Population size & Populatiegrootte (in $\mathrm{km}^{2}$ of in individuen) \\
\hline 6.3 Type of estimation & Type schatting (schatting, gemiddelde, $95 \%$-interval of minimum) \\
\hline 6.4 Additional population size & Populatiegrootte in een andere eenheid (meestal individuen) \\
\hline 6.5 Type of estimation & Type schatting (schatting, gemiddelde, 95\%-interval of minimum) \\
\hline 6.6 Method used population size & Methode waarmee de populatiegrootte is bepaald \\
\hline 6.7 Short-term trend period & 12-jarige trendperiode \\
\hline 6.8 Short-term trend direction & Richting van de trend \\
\hline 6.9 Short-term trend magnitude & Magnitude van de trend (optioneel) \\
\hline 6.10 Short-term trend method used & Methode waarmee de trend is berekend \\
\hline 6.11 Long-term trend period & 24 jarige trendperiode (optioneel) \\
\hline 6.12 Long-term trend direction & Richting van de trend (optioneel) \\
\hline 6.13 Long-term trend magnitude & Magnitude van de trend (optioneel) \\
\hline 6.14 Long-term trend method used & Methode waarmee de trend is berekend (optioneel) \\
\hline 6.15 Favourable reference population & Huidige populatiegrootte t.o.v. Favourable Reference Population \\
\hline 6.16 Change and reason for change & Verschil met vorige rapportage \\
\hline 6.17 Additional information & Ruimte voor toelichting \\
\hline
\end{tabular}

\subsubsection{Populatiegrootte}

De populatiegrootte moest worden opgegeven in de eenheid die werd voorgeschreven door de EU. Voor de meeste soorten was dat deze keer in $\mathrm{km}^{2}$ (1x1 km-gridcellen), in tegenstelling tot de vorige rapportage, toen de voorgeschreven eenheid voor de meeste soorten individuen was. Nu hoefden slechts bever, boommarter, bruinvis, bunzing, gewone zeehond, grijze zeehond, groenknolorchis, hamster, ingekorven vleermuis, meervleermuis, noordse woelmuis, vale vleermuis, witsnuitdolfijn en wolfsklauw in individuen gerapporteerd te worden.

Van de overige soorten werd de populatiegrootte ingevuld in $\mathrm{km}^{2}$. Het in te vullen getal werd direct berekend uit het databestand dat ook ten grondslag lag aan de verspreidingskaarten. Daarom gold als periode ook weer 2012-2017. Alle kilometerhokken met een waarneming werden opgeteld. Hierbij werden later toegevoegde waarnemingen (uit andere databases dan de NDFF) wel meegeteld, maar bijgeschatte $10 \times 10 \mathrm{~km}$-hokken niet. Op verzoek van LNV is later voor de soorten waarvoor dat mogelijk was ook nog de populatiegrootte in individuen ingevuld als alternatieve populatie-eenheid bij onderdeel 6.4 .

In de meeste gevallen is bij 'Type schatting' gekozen voor 'Best estimate'. In een heel enkel geval paste een ander type schatting beter, bijvoorbeeld 'Minimum' voor de meerkikker, die vaak niet helemaal op naam gebracht wordt maar dan als 'Groene kikker-complex' wordt geregistreerd. 


\subsubsection{Trend}

De populatietrend voor de periode 2006-2017 (short-term trend) is voor zover mogelijk berekend door het CBS uit tellingen van het Netwerk Ecologische Monitoring (NEM). Voor sommige soorten was niet voldoende data beschikbaar om een populatietrend te berekenen, maar lukte het wel om een verspreidingstrend te berekenen op een schaal van kilometerhokken. In beide gevallen is bij methode gekozen voor Complete survey or statistically robust estimate. In de toelichting bij veld 6.17 is aangegeven of het om een aantalstrend of een verspreidingstrend gaat.

Wanneer niet voldoende data beschikbaar was voor het CBS om een trend te berekenen, is de trend ingeschat door de expert op basis van de beschikbare gegevens. In dat geval is bij methode gekozen voor Based mainly on extrapolation from a limited amount of data of Based mainly on expert opinion with very limited data. In een enkel geval was er niet voldoende data beschikbaar voor het inschatten van de trend en is gekozen voor onbekend (Insufficient or no data available). De herkomst van de trend is toegelicht bij onderdeel 6.17. In een enkel geval is door de expert afgeweken van de trend die door het CBS is berekend. Ook dit is altijd toegelicht bij onderdeel 6.17. De optionele onderdelen $6.9,6.11,6.12,6.13$ en 6.14 zijn niet ingevuld.

\subsubsection{Favourable Reference Population}

Voor het invullen van veld 6.15 is gekozen om te werken met operators $(<, \approx,>$ of $>>)$. Ingevuld moest worden of de FRP ongeveer gelijk is aan de huidige populatie, groter dan de huidige populatie of veel groter. De Favourable Reference Values zijn in 2014 opgesteld door Ottburg \& Van Swaay en deze waarden zijn dan ook als referentiewaarden gebruikt. Wanneer de huidige populatie groter is dan de FRP moest in principe gekozen worden voor $\approx$. De operator < mocht alleen gekozen worden als de huidige populatie zoveel te groot is dat deze een bedreiging wordt voor zichzelf (bijvoorbeeld door voedseltekort). Hier is geen gebruik van gemaakt.

\subsubsection{Verschil met vorige rapportage}

$\mathrm{Bij}$ onderdeel 6.16 is aangegeven of de huidige populatiegrootte verschilde van de populatiegrootte in de vorige rapportage. Omdat er bij de soorten die nu in $\mathrm{km}^{2}$ gerapporteerd moesten worden niet vergeleken kon worden met de vorige rapportage, is bij deze soorten standaard Use of different method ingevuld als belangrijkste reden van verandering. Daarnaast kon ook nog gekozen worden voor werkelijke verandering of toegenomen kennis. De reden van verandering is toegelicht in veld 6.17 .

\subsection{Natura 2000}

Tabel 4.2 Beschrijving rapportage-onderdeel 12; Natura 2000.

\begin{tabular}{ll} 
Rapportage-onderdelen & Beschrijving \\
\hline $\mathbf{2}$ Natura $\mathbf{2 0 0 0}$ & \\
\hline 12.1 Population size & Populatiegrootte (in $\mathrm{km}^{2}$ of in individuen) \\
\hline 12.2 Type of estimate & Type schatting (schatting, gemiddelde, $95 \%$-interval of minimum) \\
\hline 12.3 Method used & Methode waarmee de populatiegrootte is bepaald \\
\hline 12.4 Short-term trend direction & 12-jarige trendperiode \\
\hline 12.5 Method used & Methode waarmee de trend is berekend \\
\hline 12.6 Additional information & Ruimte voor toelichting \\
\hline
\end{tabular}

De onderdelen voor de populatiegrootte en populatietrend binnen het Natura 2000-netwerk zijn op dezelfde wijze ingevuld als bij het onderdeel Population, alleen zijn bij de berekeningen de grenzen van het Natura 2000-netwerk gebruikt in plaats van de grenzen van Nederland. De onderdelen 12.1 $\mathrm{t} / \mathrm{m} 12.5$ zijn equivalent aan respectievelijk 6.2, 6.3, 6.6, 6.7 en 6.10. Deze sectie is alleen ingevuld voor de soorten van Annex II. 


\section{Methodiek en data Habitat, Pressures en Measures}

Het onderdeel Habitat is ingevuld met als basis de informatie over de Pressures (huidige drukfactoren in de rapportageperiode 2012-2017) en de Threats (toekomstige bedreigingen in de volgende twee rapportageperioden 2019-2030) (tabel 5.1, 5.2 en 5.3).

\subsection{Habitat}

Tabel 5.1 Beschrijving rapportage-onderdeel 7; leefgebied.

\begin{tabular}{ll} 
Rapportage-onderdelen & Beschrijving \\
7. Habitat for the species & \\
\hline 7.1 Sufficiency of area and quality of occupied habitat & Zijn oppervlak en kwaliteit van het leefgebied voldoende? \\
\hline 7.2 Method used & Methode waarmee het antwoord op 7.1 is bepaald \\
\hline 7.3 Short-term trend period & 12 -jarige trendperiode \\
\hline 7.4 Short-term trend direction & Richting van de trend \\
\hline 7.5 Short-term trend method used & Methode waarmee de trend is berekend \\
\hline 7.6 Long-term trend period & 24 jarige trendperiode (optioneel) \\
\hline 7.7 Long-term trend direction & Richting van de trend (optioneel) \\
\hline 7.8 Long-term trend method used & Methode waarmee de trend is berekend (optioneel) \\
\hline 7.9 Additional information & Ruimte voor toelichting \\
\hline
\end{tabular}

Om onderdeel 7.1 in te vullen, moesten zowel het oppervlak als de kwaliteit van het leefgebied beoordeeld worden. Hiertoe hadden we een beslisboom opgesteld die in de handleiding (Bijlage 2) uitgewerkt is. De beslisboom had tot doel dat alle experts de vragen op dezelfde wijze zouden beantwoorden. De vraag 'Are area and quality of occupied habitat sufficient for long-term survival?' werd met NEE beantwoord als minstens één van de ingevulde Pressures (zie paragraaf 5.2) erop duidde dat oppervlak of kwaliteit van het leefgebied niet voldoende was of als andere bronnen (zoals leefgebiedkaarten of kansenkaarten) daarop duidden. Indien er niet voldoende bronnen voorhanden waren, werd de vraag beantwoord op basis van expert judgement.

De habitattrend (2006-2017) werd ingeschat op basis van expert judgement. De trend moest worden samengesteld uit de trends voor oppervlakte en kwaliteit. Eerst werden beide trends apart ingeschat, daarna werden ze gecombineerd volgens de tabel in de handleiding. Bij methode is meestal gekozen voor Based mainly on extrapolation from a limited amount of data of Based mainly on expert opinion with very limited data. In sommige gevallen was er niet voldoende data beschikbaar voor het inschatten van de trend en is gekozen voor onbekend (Insufficient or no data available). In een heel enkel geval, bij enkele goed onderzochte soorten, was voldoende onderbouwing om te kiezen voor Complete survey or statistically robust estimate. In veld 7.9 is de samenstelling van de trend toegelicht. De optionele onderdelen 7.6, 7.7 en 7.8 zijn niet ingevuld.

\subsection{Pressures and Threats}

Tabel 5.2 Beschrijving rapportage-onderdeel 8; drukfactoren en bedreigingen.

\begin{tabular}{ll} 
Rapportage-onderdelen & Beschrijving \\
8. Main pressures and threats & \\
\hline 8.1 Characterisation of pressures and threats & Drukfactoren en bedreigingen met hun ranking $(\mathrm{H}$ of $\mathrm{M})$ \\
\hline 8.2 Sources of information & Informatiebronnen voor alleen dit onderdeel \\
\hline 8.3 Additional information & Ruimte voor toelichting \\
\hline
\end{tabular}


Bij onderdeel 8.1 mochten maximaal tien drukfactoren (hebben nú effect op de soort) en tien bedreigingen (zullen in de toekomst effect hebben op de soort) gekozen worden, waarvan bij beide categorieën maximaal vijf met High Importance $(H)$. De overige drukfactoren en bedreigingen kregen Medium Importance $(M)$. De drukfactoren en bedreigingen waren al vooraf ingevuld in de reporting tool op basis van de antwoorden van de vorige rapportage. Omdat de door de EU verstrekte lijst anders was dan de lijst van de vorige rapportage, werd door de Europese Commissie een vertaaltabel verstrekt (European Environment Agency 2018). Met behulp van deze vertaaltabel zijn de antwoorden van de vorige rapportage vertaald naar de huidige codering. Vervolgens is de lijst door Wageningen Environmental Research (WENR), in samenspraak met de provincies en Rijkswaterstaat teruggebracht tot maximaal tien drukfactoren/bedreigingen. Deze zijn ingevuld in de reporting tool. De soortexperts hebben de vooringevulde antwoorden gecontroleerd en zo nodig aangepast.

\subsection{Measures}

Tabel 5.1 Beschrijving rapportage-onderdeel 9; beschermingsmaatregelen.

\begin{tabular}{ll} 
Rapportage-onderdelen & Beschrijving \\
9. Conservation measures & \\
\hline 9.1 Status of measures & Zijn maatregelen nodig en wat is de status ervan? \\
\hline 9.2 Main purpose of the measures taken & Wat is het hoofddoel van de maatregelen? \\
\hline 9.3 Location of the measures & Worden de maatregelen genomen binnen en/of buiten N2000? \\
\hline 9.4 Response to the measures & Wanneer zal er positief effect van de maatregelen gezien worden? \\
\hline 9.5 List of main conservation measures & Welke maatregelen zijn er nodig? \\
\hline 9.6 Additional information & Ruimte voor toelichting
\end{tabular}

Dit onderdeel was alleen verplicht voor soorten van Annex II, maar mocht ook voor de andere soorten ingevuld worden. Dit is in de meeste gevallen ook gedaan. Als het antwoord bij onderdeel 9.1 JA was, moest gekozen worden uit de volgende opties:

1. Measures identified, but none yet taken

2. Measures identified and taken

3. Measures needed but cannot be identified

Er was dus geen tussenoptie waarbij je kon aangeven dat sommige maatregelen al bekend en genomen zijn, maar andere maatregelen al wel bekend, maar nog niet genomen. Er is voor de eerste optie gekozen als de belangrijkste maatregelen al bekend maar nog niet genomen zijn en voor optie 2 als de belangrijkste maatregelen wel al geïmplementeerd zijn. Bij onderdeel 9.5 mochten maximaal tien maatregelen gekozen worden. De lijst met maatregelen werd verstrekt door de EU en bevatte dezelfde coderingen als de lijst met Pressures and Threats. Tegenover een bepaalde bedreiging stond dus altijd een maatregel, wat echter niet betekende dat die maatregel dan ook gekozen moest worden. 


\section{Methodiek en data Future Prospects}

Bij het onderdeel Future Prospects werd gekeken naar de mogelijke ontwikkelingen in de "nabije toekomst", in de praktijk de periode van de komende twee rapportages (2019-2030) (tabel 6.1).

\subsection{Future prospects}

Tabel 6.1 Beschrijving rapportage-onderdeel 10; toekomstperspectief.

Rapportage-onderdelen Beschrijving

\section{Future prospects}

10.1 Future prospects of parameters Toekomstperspectief per parameter

10.2 Additional information Ruimte voor toelichting

Voor het invullen van de toekomstperspectieven werd een stappenplan gevolgd dat beschreven is in de handleiding (Bijlage 2). Eerst diende de expert een afweging te maken tussen de ingevulde bedreigingen en de maatregelen. Per onderdeel (Range, Population en Habitat) moest hij inschatten of de balans positief, negatief of neutraal zou uitslaan in de komende twaalf jaar. Vervolgens moest worden uitgegaan van de huidige staat van instandhouding om met behulp van de balans tussen bedreigingen en maatregelen te bepalen of het toekomstperspectief 'good', 'poor' of 'bad' was. Een matrix daarvoor is opgenomen in de handleiding. Hoe de soortexperts hun beslissingen hebben genomen, is toegelicht in veld 10.2 . 



\section{$7 \quad$ Methodiek en data Conclusions}

Op basis van de informatie die eerder in de rapportage is ingevuld, worden hier de conclusies getrokken die leiden tot de Staat van Instandhouding (tabel 7.1).

\subsection{Conclusions}

Tabel 7.1 Beschrijving rapportage-onderdeel 11; conclusies

\begin{tabular}{ll} 
Rapportage-onderdelen & Beschrijving \\
\hline 11.1 Range & Staat van Instandhouding Range \\
\hline 11.2 Population & Staat van Instandhouding Population \\
\hline 11.3 Habitat for the species & Staat van Instandhouding Habitat \\
\hline 11.4 Future prospects & Staat van Instandhouding Future \\
\hline 11.5 Overall assessment of conservation status & Staat van Instandhouding Totaal \\
\hline 11.6 Overall trend in conservation status & Totale trend \\
\hline 11.7 Change and reasons for change & Verschil met vorige rapportage \\
\hline 11.8 Additional information & Ruimte voor toelichting \\
\hline
\end{tabular}

De conclusies bij de velden 11.1, 11.2, 11.3, 11.4, 11.5 en 11.6 volgen logischerwijs uit wat er eerder is ingevuld in de rapportage. Voor het bepalen van de totale trend (veld 11.6) werd deze keer een matrix verstrekt door de EU, in tegenstelling tot de vorige rapportage toen deze vraag op basis van expert judgement moest worden ingevuld. De matrix is opgenomen in de handleiding (Bijlage 2). Bij onderdeel 11.7 is ingevuld of de Staat van Instandhouding nu verschilt van die van de vorige rapportage en zo ja, wat dan de reden is voor die verandering. In onderdeel 11.8 wordt de reden van verandering toegelicht. 



\section{Literatuur}

DG Environment, 2017. Reporting under Article 17 of the Habitats Directive: Explanatory notes and guidelines for the period 2013-2018. Final version, May 2017. Brussels. https://circabc.europa.eu/d/a/workspace/SpacesStore/d0eb5cef-a216-4cad-8e776e4839a5471d/Reporting\%20guidelines\%20Article\%2017\%20final\%20May\%202017.pdf

Ottburg, F.G.W.A., and C.A.M. van Swaay (red.). 2014. Gunstige referentiewaarden voor populatieomvang en verspreidingsgebied van soorten van bijlage II, IV en $\mathrm{V}$ van de Habitatrichtlijn. Wettelijke Onderzoekstaken Natuur \& Milieu, WOt-rapport 124, Wageningen.

European Environment Agency. 2018. Reference Portal for reporting under Article 17 of the Habitats Directive. http://cdr.eionet.europa.eu/help/habitats_art17

Schmidt, A.M., and A.S. Adams. 2015. Documentatie Habitatrichtlijn-rapportage artikel 17, $2007-$ 2012. Wettelijke Onderzoekstaken Natuur \& Milieu, WOt-technical report 55, Wageningen. 



\section{Verantwoording}

WOt-technical report: 170

Projectnummer: WOT-04-009-034.34

Aan dit project heeft een groot team van deskundigen vanuit verschillende organisaties meegewerkt. De projectleiding was in handen van Sandra Clerkx en Anne Schmidt (WENR). Daarnaast was er een technische begeleidingscommissie, waarin naast de opdrachtgevers en de projectleiding ook het CBS, enkele afgevaardigden vanuit de provincies en de trekkers van de andere rapportage-onderdelen (Annex D en Vogelrichtlijn) zitting hadden. Het vervaardigen van de verspreidingskaarten, leveren van technische ondersteuning en het doen van een consistentiecheck waren in handen van WENR.

De rapportageformats zijn ingevuld door de in het rapport bij naam genoemde soortexperts, vaak bijgestaan door collega's van de betreffende soortenorganisaties. De auteurs bedanken allen voor hun bijdrage aan het tot stand komen van deze rapportage.

Akkoord Referent/ Extern contactpersoon

functie: Beleidsmedewerker Kennis \& Systeem Natura 2000

naam: Annemiek Adams

datum: $\quad 10$ februari 2020

Akkoord Intern contactpersoon

naam: Anne Schmidt

datum: $\quad 9$ februari 2020 



\section{Bijlage 1 Soortenlijst}

\begin{tabular}{|c|c|c|c|c|c|}
\hline Soortgroep & Expert & Code & Soortnaam & Wetenschappelijke naam & Annex \\
\hline weekdieren & $\begin{array}{l}\text { Adriaan Gmelig } \\
\text { Meyling }\end{array}$ & 1014 & Nauwe korfslak & Vertigo angustior & II \\
\hline weekdieren & $\begin{array}{l}\text { Adriaan Gmelig } \\
\text { Meyling }\end{array}$ & 1016 & Zeggekorfslak & Vertigo moulinsiana & II \\
\hline weekdieren & $\begin{array}{l}\text { Adriaan Gmelig } \\
\text { Meyling }\end{array}$ & 1026 & Wijngaardslak & Helix pomatia & $\mathrm{V}$ \\
\hline ringworm & Bram Koese & 1034 & Medicinale bloedzuiger & Hirudo medicinalis & V \\
\hline libellen & Roy van Grunsven & 1037 & Gaffellibel & Ophiogomphus cecilia & $\begin{array}{l}\text { II en } \\
\text { IV }\end{array}$ \\
\hline libellen & Roy van Grunsven & 1038 & Oostelijke witsnuitlibel & Leucorrhinia albifrons & IV \\
\hline libellen & Roy van Grunsven & 1040 & Rivierrombout & Stylurus flavipes & IV \\
\hline libellen & Roy van Grunsven & 1042 & Gevlekte witsnuitlibel & Leucorrhinia pectoralis & $\begin{array}{l}\text { II en } \\
\text { IV }\end{array}$ \\
\hline libellen & Roy van Grunsven & 1048 & Groene glazenmaker & Aeshna viridis & IV \\
\hline dagvlinders & Irma Wynhoff & 1059 & Pimpernelblauwtje & Maculinea teleius & $\begin{array}{l}\text { II en } \\
\text { IV }\end{array}$ \\
\hline dagvlinders & Henk de Vries & 1060 & Grote vuurvlinder & Lycaena dispar & $\begin{array}{l}\text { II en } \\
\text { IV }\end{array}$ \\
\hline dagvlinders & Irma Wynhoff & 1061 & Donker pimpernelblauwtje & Maculinea nausithous & $\begin{array}{l}\text { II en } \\
\text { IV }\end{array}$ \\
\hline nachtvlinders & Jurriën van Deijk & 1076 & Teunisbloempijlstaart & Proserpinus proserpina & IV \\
\hline geleedpotigen & Bram Koese & 1081 & $\begin{array}{l}\text { Brede geelgerande } \\
\text { waterroofkever }\end{array}$ & Dytiscus latissimus & $\begin{array}{l}\text { II en } \\
\text { IV }\end{array}$ \\
\hline geleedpotigen & Bram Koese & 1082 & $\begin{array}{l}\text { Gestreepte } \\
\text { waterroofkever }\end{array}$ & Graphoderus bilineatus & $\begin{array}{l}\text { II en } \\
\text { IV }\end{array}$ \\
\hline geleedpotigen & John Smit & 1083 & Vliegend hert & Lucanus cervus & ॥ \\
\hline geleedpotigen & Bram Koese & 1091 & Europese rivierkreeft & Astacus astacus & V \\
\hline vissen & Erwin Winter & 1095 & Zeeprik & Petromyzon marinus & II \\
\hline vissen & Jan Kranenbarg & 1096 & Beekprik & Lampetra planeri & II \\
\hline vissen & Erwin Winter & 1099 & Rivierprik & Lampetra fluviatilis & II en $\mathrm{V}$ \\
\hline vissen & Erwin Winter & 1103 & Fint & Alosa fallax & II en $\mathrm{V}$ \\
\hline vissen & Erwin Winter & 1106 & Zalm & Salmo salar & II en $\mathrm{V}$ \\
\hline vissen & Erwin Winter & 1113 & Houting & Coregonus oxyrhynchus & V \\
\hline vissen & Jan Kranenbarg & 1145 & Grote modderkruiper & Misgurnus fossilis & II \\
\hline amfibieën & Raymond Creemers & 1166 & Kamsalamander & Triturus cristatus & $\begin{array}{l}\text { II en } \\
\text { IV }\end{array}$ \\
\hline amfibieën & Raymond Creemers & 1191 & Vroedmeesterpad & Alytes obstreticans & IV \\
\hline amfibieën & Raymond Creemers & 1193 & Geelbuikvuurpad & Bombina variegata & $\begin{array}{l}\text { II en } \\
\text { IV }\end{array}$ \\
\hline amfibieën & Raymond Creemers & 1197 & Knoflookpad & Pelobates fuscus & IV \\
\hline amfibieën & Raymond Creemers & 1203 & Boomkikker & Hyla arborea & IV \\
\hline amfibieën & Raymond Creemers & 1213 & Bruine kikker & Rana temporaria & $\mathrm{V}$ \\
\hline amfibieën & Raymond Creemers & 1214 & Heikikker & Rana arvalis & IV \\
\hline reptielen & Raymond Creemers & 1256 & Muurhagedis & Podarcis muralis & IV \\
\hline reptielen & Raymond Creemers & 1261 & Zandhagedis & Lacerta agilis & IV \\
\hline reptielen & Raymond Creemers & 1283 & Gladde slang & Coronella austriaca & IV \\
\hline vleermuizen & Herman Limpens & 1309 & Gewone dwergvleermuis & Pipistrellus pipistrellus & IV \\
\hline vleermuizen & Herman Limpens & 1312 & Rosse vleermuis & Nyctalus noctula & IV \\
\hline vleermuizen & Herman Limpens & 1314 & Watervleermuis & Myotis daubentonii & IV \\
\hline vleermuizen & Herman Limpens & 1317 & Ruige dwergvleermuis & Pipistrellus nathusii & IV \\
\hline vleermuizen & Herman Limpens & 1318 & Meervleermuis & Myotis dasycneme & $\begin{array}{l}\text { II en } \\
\text { IV }\end{array}$ \\
\hline vleermuizen & Herman Limpens & 1320 & Brandt's vleermuis & Myotis brandtii & IV \\
\hline vleermuizen & Herman Limpens & 1321 & Ingekorven vleermuis & Myotis emarginatus & $\begin{array}{l}\text { II en } \\
\text { IV }\end{array}$ \\
\hline
\end{tabular}




\begin{tabular}{|c|c|c|c|c|c|}
\hline vleermuizen & Herman Limpens & 1322 & Franjestaart & Myotis nattereri & IV \\
\hline vleermuizen & Herman Limpens & 1324 & Vale vleermuis & Myotis myotis & $\begin{array}{l}\text { II en } \\
\text { IV }\end{array}$ \\
\hline vleermuizen & Herman Limpens & 1326 & $\begin{array}{l}\text { Gewone } \\
\text { grootoorvleermuis }\end{array}$ & Plecotus auritus & IV \\
\hline vleermuizen & Herman Limpens & 1327 & Laatvlieger & Eptesicus serotinus & IV \\
\hline vleermuizen & Herman Limpens & 1329 & Grijze grootoorvleermuis & Plecotus austriacus & IV \\
\hline vleermuizen & Herman Limpens & 1330 & Baardvleermuis & Myotis mystacinus & IV \\
\hline vleermuizen & Herman Limpens & 1331 & Bosvleermuis & Nyctalus leisleri & IV \\
\hline vleermuizen & Herman Limpens & 1332 & Tweekleurige vleermuis & Vespertilio murinus & IV \\
\hline zoogdieren & Vilmar Dijkstra & 1337 & Bever & Castor fiber & $\begin{array}{l}\text { II en } \\
\text { IV }\end{array}$ \\
\hline zoogdieren & Maurice La Haye & 1339 & Hamster & Cricetus cricetus & IV \\
\hline zoogdieren & Dick Bekker & 1340 & Noordse woelmuis & $\begin{array}{l}\text { Microtus oeconomus } \\
\text { arenicola }\end{array}$ & $\begin{array}{l}\text { II en } \\
\text { IV }\end{array}$ \\
\hline zoogdieren & Dick Bekker & 1341 & Hazelmuis & Muscardinus avellanarius & IV \\
\hline zoogdieren & Maurice La Haye & 1351 & Bruinvis & Phocaena phocaena & $\begin{array}{l}\text { II en } \\
\text { IV }\end{array}$ \\
\hline zoogdieren & Vilmar Dijkstra & 1355 & Otter & Lutra lutra & $\begin{array}{l}\text { II en } \\
\text { IV }\end{array}$ \\
\hline zoogdieren & Vilmar Dijkstra & 1357 & Boommarter & Martes martes & V \\
\hline zoogdieren & Vilmar Dijkstra & 1358 & Bunzing & Mustela putorius & V \\
\hline zoogdieren & Maurice La Haye & 1364 & Grijze zeehond & Halichoerus grypus & II en V \\
\hline zoogdieren & Maurice La Haye & 1365 & Gewone zeehond & Phoca vitulina & II en V \\
\hline (korst)mossen & Laurens Sparrius & 1378 & Rendiermos (5 soorten) & Cladonia (Cladina) subsp. & V \\
\hline (korst)mossen & Laurens Sparrius & 1387 & Tonghaarmuts & Orthotrichum rogeri & II \\
\hline (korst)mossen & Laurens Sparrius & 1400 & Kussentjesmos & Leucobryum glaucum & V \\
\hline (korst)mossen & Laurens Sparrius & 1409 & Veenmos (30 soorten) & Sphagnum spp. & V \\
\hline planten & Baudewijn Ode & 1413 & Wolfsklauw (5 soorten) & Lycopodium spp. & $\mathrm{V}$ \\
\hline planten & Baudewijn Ode & 1614 & Kruipend moerasscherm & Apium repens & $\begin{array}{l}\text { II en } \\
\text { IV }\end{array}$ \\
\hline planten & Baudewijn Ode & 1762 & Valkruid & Arnica montana & V \\
\hline planten & Baudewijn Ode & 1831 & Drijvende waterweegbree & Luronium natans & $\begin{array}{l}\text { II en } \\
\text { IV }\end{array}$ \\
\hline planten & Baudewijn Ode & 1903 & Groenknolorchis & Liparis loeselii & $\begin{array}{l}\text { II en } \\
\text { IV }\end{array}$ \\
\hline zoogdieren & Maurice La Haye & 2032 & Witsnuitdolfijn & Lagenorhynchus albirostris & IV \\
\hline weekdieren & $\begin{array}{l}\text { Adriaan Gmelig } \\
\text { Meyling }\end{array}$ & 4056 & Platte schijfhoren & Anisus vorticulus & $\begin{array}{l}\text { II en } \\
\text { IV }\end{array}$ \\
\hline vissen & Erwin Winter & 5085 & Barbeel & Barbus barbus & V \\
\hline vissen & Jan Kranenbarg & 5339 & Bittervoorn & Rhodeus amarus & II \\
\hline libellen & Roy van Grunsven & 6182 & Noordse winterjuffer & Sympecma paedisca & IV \\
\hline nachtvlinders & Jurriën van Deijk & 6199 & Spaanse vlag & Euplagia quadripunctaria & II \\
\hline (korst)mossen & Laurens Sparrius & 6216 & Geel schorpioenmos & Hamatocaulis vernicosus & II \\
\hline amfibieën & Raymond Creemers & 6284 & Rugstreeppad & Epidalea calamita & IV \\
\hline amfibieën & Raymond Creemers & 6938 & Meerkikker & Pelophylax ridibundus & V \\
\hline vissen & Jan Kranenbarg & 6963 & Kleine modderkruiper & Cobitis taenia Complex & II \\
\hline vissen & Jan Kranenbarg & 6965 & Rivierdonderpad & Cottus gobio all others & II \\
\hline amfibieën & Raymond Creemers & 6976 & Bastaardkikker & Pelophylax esculentus & $\mathrm{V}$ \\
\hline amfibieën & Raymond Creemers & 6981 & Poelkikker & Pelophylax lessonae & IV \\
\hline
\end{tabular}




\section{Bijlage 2 Handleiding voor de Artikel 17 rapportage 2019}

\section{NATIONAL LEVEL}

\section{General information}

\subsection{Member State}

Use two digit code according to list in the Reference Portal

$\mathrm{NL}$

\subsection{Species code}

Use four-character sequential code according to list in the Reference Portal

Kies bij 1.3 de wetenschappelijke naam van de soort die je gaat doen. De 4-cijferige code van de soort wordt hier dan vanzelf ingevuld.

\subsection{Species scientific name}

Select species name from species checklist in the Reference Portal (recommended name)

Kies de wetenschappelijke naam van de soort die je gaat doen uit de lijst.

\begin{tabular}{l|l}
$\begin{array}{l}1.4 \text { Alternative species scientific } \\
\text { name }\end{array}$ & $\begin{array}{l}\text { Scientific name used at the national level if different } \\
\text { to } 1.3\end{array}$ \\
\hline
\end{tabular}

Wanneer de wetenschappelijke naam die in Nederland gebruikt wordt anders is dan wat is ingevuld bij 1.3, vul deze dan hier in. Is dit niet zo, laat dit vakje dan leeg.

\subsection{Common name \\ Optional \\ In national language}

Vul hier de gangbare Nederlandse naam in (is meestal al ingevuld).

\section{Maps}

Achtergrondinformatie over de kaarten uit de 'Explanatory Notes and Guidelines (Final Version, May 2017, blz. 25 en 123):

The distribution map should provide information about the actual occurrences of the species, which should preferably be based on the results of a comprehensive national mapping or inventory of the species wherever possible. If field data on actual occurrences of the species are not sufficient, modelling and extrapolation should be used whenever feasible. The distribution map will be though composed of grids with both the actual (mapped) and presumed species occurrences.

The gridded dataset will consist only of the $10-\mathrm{km}$ grid cells where the species is recorded or estimated as occurring; the use of attribute data to indicate the presence or absence of a species in a grid cell is not permitted.

Species are occasionally recorded beyond their usual area of distribution, but these occasional records should not influence the shape and size of the range, nor should they be counted when weighting by the species distribution during the EU biogeographical assessment. Therefore, the distribution map is based only on regular occurrences of the species (except for maps of 'occasional' or 'newly arriving' species. On the other hand, particularly on the boundaries of the natural geographical range, species may occur in limited numbers in atypical conditions. These outliers should be included in the distribution of the species if they represent regular and/or stable occurrences, as they are important for calculating the range.

Afspraak over uitgezette populaties:

Bij (her)introductie BINNEN het natuurlijke verspreidingsgebied maakt het eigenlijk niet uit of ze legaal of illegaal zijn (mits ze zich kunnen handhaven). Dan blijft de vraag over wat het natuurlijk verspreidingsgebied is. De facto zeggen we dat het natuurlijk verspreidingsgebied is waar de soort 100 jaar geleden voorkwam alsmede natuurlijke uitbreidingen van daaruit (ook al was het oorspronkelijk een illegale herintroductie buiten het toenmalige natuurlijke verspreidingsgebied). 
WEL:

Inheemse populaties, dat wil zeggen binnen het natuurlijke historische verspreidingsgebied of natuurlijke uitbreidingen daarvan.

- Uitgezette populaties binnen het natuurlijke historische verspreidingsgebied als ze zich minimaal vijf jaar zelfstandig hebben weten te handhaven.

Uitgezette populaties buiten het natuurlijke historische verspreidingsgebied als ze zich meer dan 100 jaar zelfstandig hebben weten te handhaven (bijv. wijngaardslak).

NIET:

(her)introducties jonger dan 100 jaar geleden BUITEN het natuurlijke verspreidingsgebied. Als onduidelijk is of een populatie uitgezet is of niet, doet hij wel mee.

\subsection{Sensitive species}

Some species are particularly subject to, for example, illegal collecting, and making information on their distribution widely available may be detrimental to their conservation. Enter YES if the species is considered as 'sensitive' and NO if it is not considered as 'sensitive'.

Vul NO/YES in (standaard is NO, vul alleen YES in als daar een goede reden voor is).

2.2 Year or period 2012-2017

\subsection{Distribution map}

Year or period when the distribution data was collected

Submit a map together with relevant metadata following the technical specifications in the Explanatory notes and guidelines. The standard for species distribution is $10 \times 10 \mathrm{~km}$ ETRS89 grid cells, projection ETRS LAEA 5210.

De eerste controleronde van de kaarten is vóór de zomer geweest. Controleer nogmaals de nieuwe kaarten op de volgende twee aspecten:

1) Staan er nog hokken teveel op, bijvoorbeeld van zwervers?

2) Staan er hokken te weinig op waar geen waarnemingen zijn gedaan maar die op basis van expertkennis wel ingekleurd kunnen worden?

\subsection{Method used}

a) = Complete survey or a statistically robust estimate

b) = Based mainly on extrapolation from a limited amount of data

c) = Based mainly on expert opinion with very limited data

d) = Insufficient or no data available

Kies de methode die het beste de situatie omschrijft waarmee de kaart tot stand is gekomen. Voor de meeste soorten kunnen wij kaarten maken volgens methode a. In overleg met de soortexperts zijn sommige kaarten verbeterd (methode b), bijv. bij de trekvissen of sommige vleermuissoorten. Van de riviertrekvissen (fint, rivierprik, zalm en zeeprik), die zich allemaal voortplanten in zoet water, maar het grootste deel van hun leven verblijven in zout water, is bekend dat deze vaste migratiebanen volgen. Deze banen worden conform de voorschriften van de EC gebruikt voor de rapportage. Deze vissen komen zowel in zoet als in zout water voor, maar voor de rapportage worden alleen de hokken in het zoete water meegenomen.

\subsection{Additional maps Optional} Member States can submit an additional map, deviating from standard submission map under 2.3 and/or a range map if they wish

Optioneel, niet invullen. 


\section{Information related to Annex V species (Art. 14) (alleen invullen}

\section{voor Annex V)}

3.1 Is the species

taken in the

wild/exploited?

\section{YES/NO}

If the reply is NO, or if the reply is YES and the conservation status of the species is Favourable (FV) in all biogeographical or marine regions where the species occurs, then do not fill in the remaining fields of this section.

If the reply is YES and the conservation status of the species is unfavourable (U1 or U2) in one or more biogeographical/marine regions where the species occurs, please complete the remaining relevant fields of this section.

Vul YES in als de soort verzameld, gevangen of bejaagd mag worden, of als de soort ondanks een verbod in de praktijk toch verzameld, gevangen of bejaagd wordt. Vul NO in als de soort niet verzameld, gevangen of bejaagd wordt.

Wanneer je YES hebt ingevuld en de staat van instandhouding van de soort is ongunstig (dit ga je invullen bij 11.5), vul dan de rest van dit formulier in. Bij NO en/of een gunstige staat van instandhouding hoeft de rest van dit onderdeel niet ingevuld te worden.

\subsection{Which of the} measures in Art. 14 have been taken?

\begin{tabular}{|l|l|}
\hline a) regulations regarding access to property & $Y E S / N O$ \\
\hline $\begin{array}{l}\text { b) temporary or local prohibition of the taking of specimens } \\
\text { in the wild and exploitation }\end{array}$ & $Y E S / N O$ \\
\hline $\begin{array}{l}\text { c) regulation of the periods and/or methods of taking } \\
\text { specimens }\end{array}$ & $Y E S / N O$ \\
\hline $\begin{array}{l}\text { d) application of hunting and fishing rules which take } \\
\text { account of the conservation of such populations }\end{array}$ & $Y E S / N O$ \\
\hline $\begin{array}{l}\text { e) establishment of a system of licences for taking } \\
\text { specimens or of quotas }\end{array}$ & $Y E S / N O$ \\
\hline $\begin{array}{l}\text { f) regulation of the purchase, sale, offering for sale, keeping } \\
\text { for sale or transport for sale of specimens }\end{array}$ & $Y E S / N O$ \\
\hline $\begin{array}{l}\text { g) breeding in captivity of animal species as well as artificial } \\
\text { propagation of plant species }\end{array}$ & $Y E S / N O$ \\
\hline h) other, if YES, please describe (text field) & $Y E S / N O$ \\
\hline
\end{tabular}

Geef per maatregel aan of deze maatregel genomen is voor de soort (alleen als je YES hebt geantwoord bij 3.1).

\subsection{Hunting bag or quantity taken in the wild for Mammals and Acipenseridae (Fish)}

Provide statistics on national hunting bag or quantity taken in the wild for the reporting period

\begin{tabular}{|c|c|c|c|c|c|c|}
\hline \multirow{3}{*}{$\begin{array}{l}\text { a) Unit } \\
\text { b) } \\
\text { Statistics/quantity } \\
\text { taken }\end{array}$} & \multicolumn{6}{|c|}{ Use same unit as in field 6.2} \\
\hline & \multicolumn{6}{|c|}{$\begin{array}{l}\text { Provide statistics/quantity taken per year over } \\
\text { the reporting period }\end{array}$} \\
\hline & $\begin{array}{l}\text { Year } \\
1\end{array}$ & $\begin{array}{l}\text { Year } \\
2\end{array}$ & $\begin{array}{l}\text { Year } \\
3\end{array}$ & $\begin{array}{l}\text { Year } \\
4\end{array}$ & $\begin{array}{l}\text { Year } \\
5\end{array}$ & Year 6 \\
\hline \multicolumn{7}{|l|}{$\begin{array}{l}\text { Min. (raw, i.e. not } \\
\text { rounded) }\end{array}$} \\
\hline \multicolumn{7}{|l|}{$\begin{array}{l}\text { Max. (raw, i.e. not } \\
\text { rounded) }\end{array}$} \\
\hline Unknown & & & & & & \\
\hline
\end{tabular}


Dit zou mogelijk van het Faunaregistratiefonds kunnen komen, maar ook van provincies.

Uitleg uit de 'Explanatory Notes and Guidelines (Final Version, May 2017, blz. 27/28):

These data are provided per year/season over the length of the reporting period. For species with defined hunting, seasons report per season (if national counts are also done per season). Season 1 is 2012/2013 (starting in autumn 2012 and ending in spring 2013); Season 6 is 2017/2018.

For species which do not have hunting seasons or where national counts are elaborated per year (e.g. sturgeons), provide counts per calendar year; year 1 is 2013 and year 6 is 2018.

The raw data should be provided for the hunting bag or quantity taken and where a precise number is known this should be filled in both the 'Min.' and 'Max.' fields. If only minimum or only maximum numbers are available these should be reported in respective fields 'Min.' and 'Max.' Where the hunting bag is unknown this should be indicated in a separate field. In cases where bag statistics are only available for a group of species (mainly catches for sturgeons), without a reliable breakdown per species the proportion (e.g. $0-5 \%$ for each minority species; $50-90 \%$ for a majority one) for each species should be estimated and reported as 'Min.' and 'Max.' values. The appropriate explanation should be provided in field 3.5 'Additional information' (e.g. 'Bag statistics (min-max) were obtained for a group of species ([species 1], [species 2], [species $x$ ]), but probably $>90 \%$ relate to the species in this report'). The method used (field 3.4) should reflect the fact that actual figures reported are an approximation and should be ' $b$ ' or ' $c$ ' respectively.

\section{\begin{tabular}{l|l}
\hline 3.4 Method used & $3=$ Complete survey or a statistically robust estimate
\end{tabular} \\ 2 = Based mainly on extrapolation from a limited amount of data \\ 1 = Based mainly on expert opinion with very limited data \\ $0=$ Insufficient or no data available}

Kies de methode die het beste de situatie omschrijft waarmee de schatting uit 3.3 tot stand is gekomen. Er kan maar één methode gekozen worden. Wanneer meerdere methoden zijn gebruikt, kies dan de methode die is gebruikt voor de meest belangrijke databron.

\section{\begin{tabular}{|l|l|}
\hline 3.5 Additional & Free text
\end{tabular} information \\ Optional}

Deze ruimte kan gebruikt worden om, indien gewenst, een toelichting te geven op de ingevulde velden. 


\section{BIOGEOGRAPHICAL LEVEL}

\section{Biogeographical and marine regions}

4.1 Biogeographical or marine region where the species occurs

Choose one of the following: Alpine, Atlantic, Black Sea, Boreal, Continental, Mediterranean, Macaronesian, Pannonian, Steppic, Marine

Atlantic, Marine Mediterranean, Marine Black Sea, Marine Macaronesian and Marine Baltic Sea.

Kies in het terrestrisch gebied voor 'Atlantic' en in zout water voor 'Marine Atlantic'.

De trekvissen komen zowel in zoet als zout water voor, maar voor de rapportage worden alleen de hokken in het zoete water meegenomen. Informatie over 'Habitat kwaliteit en beschikbaarheid' en 'Drukfactoren en bedreigingen' (zie sectie 7 en 8) die specifiek zijn voor de mariene omgeving, moeten opgenomen worden in het terrestrische rapport (bron: Guidelines blz. 105).

De zeezoogdieren (bruinvis, gewone zeehond, grijze zeehond) zijn de vorige keer alleen voor MATL gerapporteerd. Soorten die overwegend terrestrisch zijn maar ook in zee kunnen voorkomen (zoals de otter) worden alleen onder de terrestrische regio gerapporteerd.

Er zijn dus geen soorten waarvoor beide regio's ingevuld hoeven te worden!

\subsection{Sources of information}

For data reported in the sections below provide relevant available bibliographic references and/or link to internet site(s)

Geef hier een lijst van publicaties die gebruikt zijn voor de secties 5-7 (ook de bronnen die gebruikt zijn voor de verspreidingskaarten waar de berekening van de range op is gebaseerd) en voor de secties 9-13. Gebruik de volgorde: auteur, jaar, titel, bron, volume, aantal pagina's, webpagina.

Geef internetadressen in z'n geheel weer, inclusief http:// of https://.

Voor de meeste soorten zal de NDFF een van de bronnen zijn: https://www.ndff.nl Voor de soorten met een trend uit het NEM kan daarvoor verwezen worden naar: http://www.netwerkecologischemonitoring.nl 


\section{Range}

Range wordt gedefinieerd als (Guidelines, blz. 29): 'the outer limits of the overall area in which a habitat type or species is found at present' and it can be considered as an envelope within which areas actually occupied occur.

\begin{tabular}{l|l} 
5.1 Surface area & $\begin{array}{l}\text { Total surface area of the current range (outer limits of the } \\
\text { species distribution) within biogeographical/marine region } \\
\text { concerned in } \mathrm{km}^{2} .\end{array}$
\end{tabular}

Dit is het aantal 10x10 km-hokken in ETRS-projectie na het opvullen m.b.v. de rangetool. Zie de 'Explanatory Notes and Guidelines (Final Version, May 2017, blz. 29-30 en 125-128):

The range should be calculated based on the map of the actual distribution using a standardised algorithm. A standardised process is needed to ensure repeatability of the range calculation in different reporting rounds and for comparison of results between Member States. It will also allow for estimating rate trends. The standardised process consists of two steps:

1. Creating an envelope(s) around distribution grids. Range should exclude major discontinuities that are natural, i.e. caused by ecological factors. A discontinuity of at least $40-50 \mathrm{~km}$ is suggested to be considered as a gap in the range.

2. Excluding unsuitable areas, such as marine areas in the range of a terrestrial species.

A gap distance should be understood as the distance between two distribution grids that will not be joined together to form a single range polygon but will be shown as discontinuities in a range. The gap distance should reflect the ecological characteristic of the species. This means that for mobile species the range will be calculated using larger gaps and, conversely, smaller gaps will be used for less mobile species.

Alterra zorgt voor de berekening van de range en voor de onderliggende kaarten. De range wordt berekend na controle van de rangekaart door de soortexpert. De kaarten hoeven niet ingeleverd te worden, maar het mag wel (bij 2.5). Omdat Nederland goed onderzocht is, gebruiken we net als in de vorige rapportage in principe een kleine gap distance van $10 \mathrm{~km}$, tenzij dit tot fouten leidt.

Voor het uitsluiten van 'unsuitable areas' geldt:

Technically, range is calculated by filling in the unoccupied grids between the cells of distribution. The following types of unsuitable areas should be excluded from the calculated range:

marine areas automatically included in the range of terrestrial species terrestrial areas automatically included in the range of marine species areas beyond national boundaries areas without water bodies for freshwater species and vice versa.

Although the distinction between suitable and unsuitable areas is very coarse, the purpose of this step is to correct only the most important contradictions resulting from automated calculation.

\begin{tabular}{l|l} 
5.2 Short-term trend & $\begin{array}{l}2007-2018 \text { (rolling 12-year time window) or period as close as } \\
\text { period }\end{array}$ \\
\hline
\end{tabular}

2006-2017

\begin{tabular}{|c|c|}
\hline $\begin{array}{l}5.3 \text { Short-term trend } \\
\text { Direction }\end{array}$ & $\begin{array}{l}\text { Indicate if range trend over the period reported in field } 5.2 \text { was: } \\
0=\text { stable } /+=\text { increasing } /-=\text { decreasing } / u=\text { uncertain } / x \\
=\text { unknown }\end{array}$ \\
\hline
\end{tabular}

Waar mogelijk gebruiken we, net als de vorige keer, de occupancytrend, gebaseerd op 10x10 kmhokken (Amersfoortcoördinaten). Waar geen occupancytrend mogelijk is, vergelijken we de waarde van de vorige rapportage (2007-2011) met de nieuwe waarde (2012-2017) en via een Chi-kwadraat toets kijken of er een significante trend is.

Voor de soorten waarvoor dit niet kan moet de expert de trend inschatten. Kies welke richting van toepassing is. Kies 'onzeker' als er wel data is, maar niet voldoende om een accurate richting te berekenen, kies 'unknown' als er geen data beschikbaar is. Fluctuatie is geen trend. Ook verandering in range door een verandering in de monitoringmethodologie of door toegenomen kennis is geen trend. Dit soort informatie moet gegeven worden in field 5.11 . 


\begin{tabular}{|c|c|c|c|}
\hline \multirow{2}{*}{$\begin{array}{l}\text { 5.4 Short-term trend } \\
\text { Magnitude } \\
\qquad \text { Optional }\end{array}$} & $\begin{array}{l}\text { a) } \\
\text { Minimum }\end{array}$ & \multicolumn{2}{|c|}{$\begin{array}{l}\text { Percentage change over the period indicated in } \\
\text { the field 5.2. If a precise value is known provide } \\
\text { the same value under both minimum and } \\
\text { maximum }\end{array}$} \\
\hline & $\begin{array}{l}\text { b) } \\
\text { Maximum }\end{array}$ & \multicolumn{2}{|c|}{$\begin{array}{l}\text { Percentage change over the period indicated in } \\
\text { the field 5.2. If a precise value is known provide } \\
\text { the same value under both minimum and } \\
\text { maximum }\end{array}$} \\
\hline \multicolumn{4}{|l|}{ Optioneel, niet invullen. } \\
\hline $\begin{array}{l}5.5 \text { Short-term trend } \\
\text { Method used }\end{array}$ & \multicolumn{3}{|c|}{$\begin{array}{l}3=\text { Complete survey or a statistically robust estimate, } 2= \\
\text { Based mainly on extrapolation from a limited amount of data, } 1 \\
=\text { Based mainly on expert opinion with very limited data, } 0= \\
\text { Insufficient or no data available }\end{array}$} \\
\hline \multicolumn{4}{|c|}{$\begin{array}{l}\text { Kies welke situatie het best van toepassing is. Voorstel: } \\
\text { - Occupancy-modellen: } 3 \\
\text { - Chi kwadraat: } 2 \\
\text { - Anders: } 1 \text { of } 0 \text {, afhankelijk van de situatie. }\end{array}$} \\
\hline $\begin{array}{l}5.6-5.9 \text { Long-term } \\
\text { trend } \\
\text { Optional }\end{array}$ & \multicolumn{3}{|c|}{ A trend calculated over 24 years (1994-2018) } \\
\hline \multicolumn{4}{|l|}{ Optioneel, niet invullen. } \\
\hline $\begin{array}{l}5.10 \text { Favourable } \\
\text { reference range }\end{array}$ & \multicolumn{3}{|c|}{$\begin{array}{l}\text { a) In } \mathrm{km}^{2} \\
\text { b) Indicate if operators were used (use these symbols } \approx,>,>>\text { ) } \\
\text { c) If favourable reference range is unknown indicate by using ' } x \text { ' } \\
\text { d) Indicate method used to set reference value if other than } \\
\text { operators } \\
\text { (free text) }\end{array}$} \\
\hline \multicolumn{4}{|c|}{$\begin{array}{l}\text { Favourable Reference Range wordt gedefinieerd als de range waarbinnen alle significante } \\
\text { ecologische variaties van de soort aanwezig zijn en die groot genoeg is voor overleving van de } \\
\text { soort op de lange termijn. } \\
\text { Er is besloten om hier in principe de operators te gebruiken. Kies de juiste operator die aangeeft } \\
\text { of de Favourable Reference Range groter, veel groter of ongeveer gelijk aan de huidige range is } \\
\text { (ingevuld bij 5.1). Als het onbekend is, vul dan een kruisje in bij c. Het invulveld bij d is optioneel } \\
\text { en hoeft niet te worden ingevuld. }\end{array}$} \\
\hline \multirow[t]{6}{*}{$\begin{array}{l}5.11 \text { Change and reason } \\
\text { for change in surface } \\
\text { area of range }\end{array}$} & \multicolumn{2}{|c|}{$\begin{array}{l}\text { a) Are there differences between values reported } \\
\text { in } 5.1 \text { compared to the previous reporting } \\
\text { period? } \\
\text { If YES select one or several of the following } \\
\text { options } b), c), d \text { ) or } e \text { ) }\end{array}$} & YES/NO \\
\hline & \multicolumn{2}{|c|}{ b) Genuine change } & YES/NO \\
\hline & \multicolumn{2}{|c|}{ c) Improved knowledge/more accurate data } & YES/NO \\
\hline & \multicolumn{2}{|c|}{ d) Use of different method } & YES/NO \\
\hline & \multicolumn{2}{|c|}{ e) No information on the nature of change } & YES/NO \\
\hline & \multicolumn{2}{|c|}{$\begin{array}{l}\text { f) Which of b), c) or } d \text { ) is the main reason for } \\
\text { change? }\end{array}$} & Report b), c) d) \\
\hline \multicolumn{4}{|c|}{$\begin{array}{l}\text { Hier moet worden aangegeven of er verandering is in het oppervlak van de range sinds de vorige } \\
\text { rapportageperiode, en als dat zo is, wat dan de aard is van de verandering. Beantwoord eerst de } \\
\text { eerste vraag. Ook een verandering van één hok betekent dat je dit al met YES moet } \\
\text { beantwoorden. Wanneer je YES antwoordt, beantwoord dan ook de rest van de vragen. Er } \\
\text { kunnen meerdere opties tegelijk gekozen worden, geef dan bij f aan wat de belangrijkste reden } \\
\text { van de verandering is. }\end{array}$} \\
\hline $\begin{array}{l}5.12 \text { Additional } \\
\text { information }\end{array}$ & \multicolumn{3}{|l|}{ Free text } \\
\hline
\end{tabular}




\section{Population}

\subsection{Year or period}

Year or period when data for population size was recorded

\section{2-2017}

\subsection{Population size}

(in agreed unit) a) Unit

b) Minimum

c) Maximum

d) Best

estimate

Agreed unit (see Reference portal)

Number (raw, i.e. not rounded). Provide at least one of interval $(b, c)$ or best estimate (d). If a precise value is known provide the same value under both minimum and maximum

Number (raw, i.e. not rounded). Provide at least one of interval $(b, c)$ or best estimate (d). If a precise value is known provide the same value under both minimum and maximum

Number (raw, i.e. not rounded). Provide at least one of interval $(b, c)$ or best estimate (d)

De 'agreed unit' is voor de meeste soorten $1 \times 1 \mathrm{~km}$-grid (grids1 $1 \times 1$ ). Voor enkele zoogdieren en planten is de unit individuen (i), namelijk voor: bever, boommarter, bruinvis, bunzing, gewone zeehond, grijze zeehond, groenknolorchis, hamster, ingekorven vleermuis, meervleermuis, noordse woelmuis, vale vleermuis, witsnuitdolfijn.

Voor de soorten waarvoor de populatiegrootte via het aantal $1 \times 1 \mathrm{~km}$ gridcellen moet worden gegeven, is dit zo mogelijk al vooraf ingevuld gebaseerd op NDFF of andere aangeleverde data.

Maak een schatting van de populatiegrootte in de vereiste eenheid (kilometerhokken of individuen) en vul dit in als minimum en maximum ( $b$ en $c$ ) of als exact getal (d). In de meeste gevallen zal het om een schatting met een minimum en maximum gaan. Beide opties invullen mag ook, bijvoorbeeld wanneer de data een intervalschatting mogelijk maken, maar er op basis van expert judgement een preciezere schatting mogelijk is. Of andersom: wanneer alleen een puntschatting voorhanden is, maar het gewenst is om daarbij ook een betrouwbaarheidsinterval te geven. Wanneer zowel een intervalschatting als een puntschatting worden ingevuld, moet dit worden uitgelegd in veld 6.17 .

Voor trekvissen schrijven de richtlijnen voor dat de hele rivier naar km-hokken moet worden omgezet (guidelines, blz. 134): Linear features: This approach can be used for species linked to rivers (or other linear features) where a locality often represents a stretch of a river with recorded species occurrence.

\subsection{Type of estimate}

Best estimate / 6-year mean / 95\% CI range / minimum

Kies de methode die het best van toepassing is (uit de guidelines, blz. 35). Als het om $1 \mathrm{~km}$ gridcellen uit de NDFF gaat, moet je kiezen voor 'best estimate', tenzij je goede redenen hebt om daarvan af te wijken (die moet je dan wel toelichten in 6.17):

best estimate: the best available single figure (including where only the maximum value of the population size is available) or interval, derived from e.g. a population census, a compilation of figures from localities, modelled population size based on population densities and distribution data or expert opinion, but for which $95 \%$ confidence interval could not be calculated. Whether a best estimate comes from the monitoring data, modelling or an expert opinion should be entered in field 6.6;

multi-year mean: average value or interval where population size is monitored several times during the period provided in field 6.1;

$95 \%$ confidence interval: estimates derived from sample surveys or a model in which $95 \%$ confidence limits could be calculated;

minimum: where insufficient data exist to provide even a loosely bounded estimate, but where a population size is known to be above a certain value, or where the reported interval estimates come from a sample survey or monitoring project which probably underestimates the real population size.

\subsection{Additional} population size (using population unit other than agreed unit) a) Unit

b) Minimum
E.g. unit to be used for assessment at national level

Number (raw, i.e. not rounded). Provide at least one of interval $(b, c)$ or best estimate (d). If a precise value is known provide the 


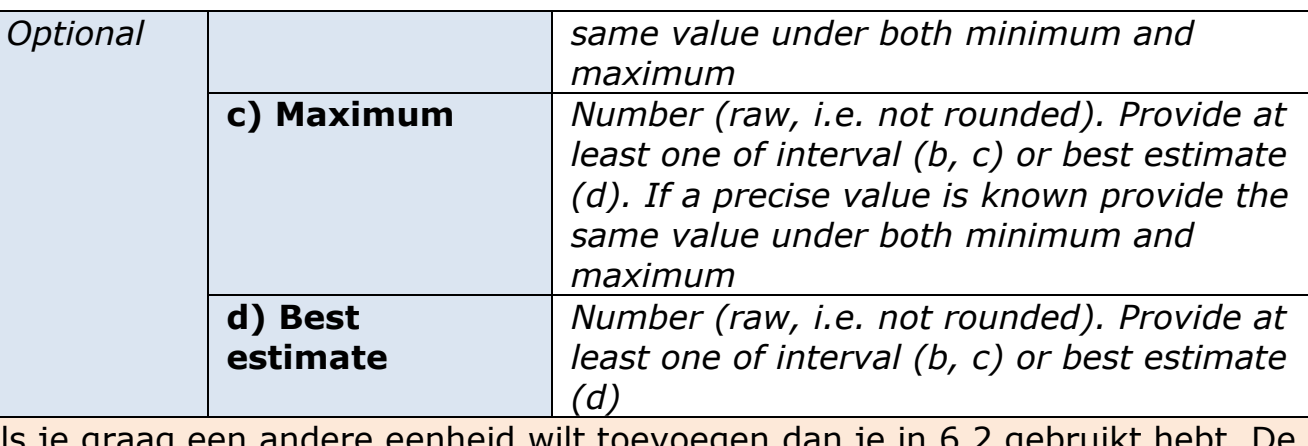

Vul deze alleen in als je graag een andere eenheid wilt toevoegen dan je in 6.2 gebruikt hebt. De waarden bij dit onderdeel zijn extra, dus niet in plaats van wat in 6.2 ingevuld moet worden.

Omdat hij optioneel is mag je hem ook overslaan.

\begin{tabular}{|l|l|}
\hline 6.5 Type of estimate & Best estimate / 6-year mean / 95\% CI range / minimum
\end{tabular}

Vul dit veld alleen in als je ook 6.4 hebt ingevuld. Zie voor uitleg bij 6.3.

\subsection{Method used Population size} 3 = Complete survey or a statistically robust estimate, $2=$
Based mainly on extrapolation from a limited amount of data, 1
$=$ Based mainly on expert opinion with very limited data, $0=$
Insufficient or no data available

Kies de optie die het best beschrijft welke methode is gebruikt om de populatiegrootte uit 6.2 te berekenen. Wanneer de gebruikte data uit verschillende bronnen komt, kies dan de methode die past bij de belangrijkste en meest betrouwbare data.

Extra toelichting in de guidelines (blz. 36):

3. complete survey or a statistically robust estimate (e.g. repeated direct counts of entire population; repeated counting based on indices of species presence; from previous complete inventory updated with robust monitoring data on trends);

2. based mainly on extrapolation from a limited amount of data (e.g. based on markrecapture methods; using models based on abundance and distribution data; using extrapolation from sample surveys of parts of the population; or from previous inventory updated with good trend data);

1. based mainly on expert opinion with very limited data;

0 . insufficient or no data available.

Grofweg hanteren we deze richtlijnen:

$1 \times 1 \mathrm{~km}$-gridsoorten:

- Voor de soorten waarvoor alle potentiële km-hokken bezocht zijn: methode=3

- Voor de soorten waarvoor een occupancy-schatting beschikbaar is of waarvoor we weten dat niet alle potentiële km-hokken zeker goed bezocht zijn, maar wel het grootste deel: methode $=2$

- Voor de soorten waarvoor dit niet het geval is: methode $=1$ of 0 .

Voor de soorten waarvoor individuen moeten worden gegeven:

- Gewone en grijze zeehond: goed bekend, methode=3

- Bruinvis en overige soorten: aan de soortexpert.

\subsection{Short-term trend Period} 2007-2018 (rolling 12-year time window) or period as close as possible to it. The short-term trend is to be used for the assessment of population

2006-2017.

\subsection{Short-term trend} Direction

Geef de richting aan van de populatietrend over de periode 2006-2017. Voor zover mogelijk zijn de resultaten uit het NEM of uit occupancyberekeningen vooraf ingevuld (zie ook bijlage 1 ). Bij 6.10 kun je dan invullen: methode $=3$.

Voor de overige soorten kon geen trend worden vastgesteld. Voor de soorten waarvoor in volwassen individuen gerapporteerd moet worden, kan een vergelijking (Chi-kwadraat) gemaakt worden met de vorige rapportage (Bij 6.10: methode $=2$ of methode $=1)$. Voor de soorten waarvoor in $1 \times 1 \mathrm{~km}$-grids gerapporteerd moet worden en geen andere data beschikbaar is, moet de expert een inschatting geven (methode $=1$ ). 
Let op: als de trend het resultaat is van een verandering in monitoringmethode of toegenomen kennis, dan moet dit aangegeven worden in 6.16. Uitleg kan gegeven worden bij 6.17.

\begin{tabular}{|c|c|c|}
\hline \multirow[t]{3}{*}{$\begin{array}{l}\text { 6.9 Short-term } \\
\text { trend } \\
\text { Magnitude }\end{array}$} & a) Minimum & $\begin{array}{l}\text { Percentage change over the period indicated in the field 6.7. If } \\
\text { a precise value is known provide the same value under both } \\
\text { minimum and maximum }\end{array}$ \\
\hline & b) Maximum & $\begin{array}{l}\text { Percentage change over the period indicated in the field 6.7. If } \\
\text { a precise value is known provide the same value under both } \\
\text { minimum and maximum }\end{array}$ \\
\hline & $\begin{array}{l}\text { c) Confidence } \\
\text { interval }\end{array}$ & $\begin{array}{l}\text { Indicate confidence interval if a statistically reliable sampling } \\
\text { scheme is used }\end{array}$ \\
\hline
\end{tabular}

\subsection{Short-term trend Method used}

$3=$ Complete survey or a statistically robust estimate, 2 = Based mainly on extrapolation from a limited amount of data, 1 = Based mainly on expert opinion with very limited data, $0=$ Insufficient or no data available

Zie toelichting bij 6.8 .

\begin{tabular}{l|l}
$\begin{array}{l}\text { 6.11 - 6.14 Long-term } \\
\text { trend } \\
\text { Optional }\end{array}$ & A trend calculated over 24 years (1994-2018) \\
Optioneel, niet invullen. &
\end{tabular}

6.15 Favourable reference population

(using agreed unit) a) Population size (using same unit as in 6.2)

b) Indicate if operators were used (using symbols $\approx,>,>>,<$ )

c) If favourable reference population is unknown indicate by using ' $x$ '

d) Indicate method used to set reference value if other than operators (free text)

De Favourable Reference Population wordt gedefinieerd als de minimale populatiegrootte die groot genoeg is voor overleving van de soort op de lange termijn. We gebruiken hier operators (optie b). Geef daarmee aan of de Favourable Reference Population kleiner $(<)$, ongeveer gelijk aan $(\approx)$, groter $(>)$ of veel groter $(>>)$ is dan de huidige waarde (ingevuld bij 6.2, gebruik hiervoor de minimumwaarde). Veld $d$ (beschrijven van de methode die is gebruikt om de referentiewaarde te bepalen) is optioneel en hoeft dan dus niet te worden ingevuld. Wanneer de referentiewaarde veranderd is ten opzichte van de vorige rapportage, dan moet de reden hiervoor beschreven worden bij 6.17 .

Opmerking uit de guidelines (blz. 38):

The operator 'less than' $(<)$ can be used only in limited cases; where a species might have developed - due to exceptional circumstances such as supplementary feeding - an exceptionally high population level far beyond that considered as favourable in normal circumstances and which is unlikely to be sustainable or which may even be detrimental to other species or habitats. If used, an explanation must be provided in field 6.17 'Additional information'.

\begin{tabular}{|l|l|l|}
\hline $\begin{array}{l}\text { 6.16 Change and reason } \\
\text { sor change in population }\end{array}$ & $\begin{array}{l}\text { a) Are there differences between values reported in 6.2 or } \\
6.4 \text { compared to the previous reporting period? } \\
\text { If YES select one or several of the following options b), c) } \\
\text { d) or e) }\end{array}$ & YES/NO \\
\hline b) Genuine change & $Y E S / N O$ \\
\hline & c) Improved knowledge/more accurate data & $Y E S / N O$ \\
\hline d) Use of different method & $Y E S / N O$ \\
\hline e) No information of the nature of change & $Y E S / N O$ \\
\hline f) Which of b), c) or d) is the main reason for change? & $\begin{array}{l}\text { Report } \\
\text { b), c) or } \\
\text { d) }\end{array}$ \\
\hline
\end{tabular}

Voor alle soorten waarvoor we nu moeten rapporteren in $1 \times 1 \mathrm{~km}$-grid, is er sprake van d: use of different method (vorige rapportageperiode is immers vrijwel alles in individuen gerapporteerd). De aantallen zullen namelijk fors anders zijn dan het aantal $1 \mathrm{~km}$ gridcellen. 
Voor de soorten waarvoor ook nu in volwassen individuen gerapporteerd moet worden, moet je a) al met YES beantwoorden als er een verschil is van één individu. Vul dan b) t/m f) ook in.

\subsection{Additional information \\ Optional \\ Other relevant information (e.g. method to convert population size unit as used for monitoring into the agreed population unit as referred under 6.2) \\ Free text}

Ruimte voor extra toelichting wanneer dat kan helpen om de informatie uit dit onderdeel beter te begrijpen.

Wanneer de referentiewaarde bij 6.15 veranderd is ten opzichte van de vorige rapportage, dan moet de reden daarvoor hier beschreven worden.

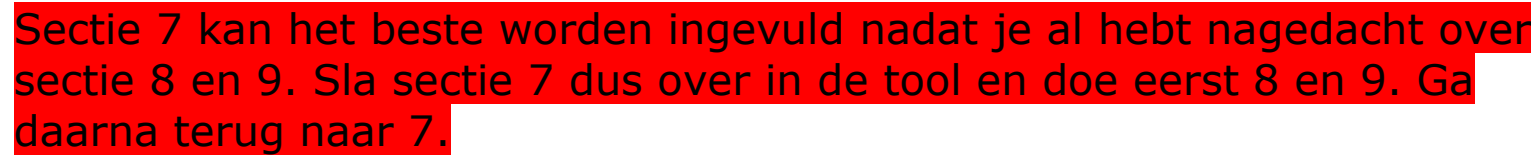




\section{Main pressures and threats}

\subsection{Characterisation of pressures/threats}

\section{a) Pressure/threat}

List pressures/threats using the code list provided on the reference portal

\section{b) Ranking of pressure/threat}

Indicate whether the pressure/threat is of:

$H=$ high importance

$M=$ medium importance

Kies maximaal 10 pressures en maximaal 10 threats uit de lijst en geef elke keuze een ranking (high importance $(\mathrm{H})$ of medium importance $(\mathrm{M})$ ). De pressures en threats zijn al vooringevuld op basis van de vorige rapportage. Controleer dit en pas naar eigen inzicht aan. De uitgebreide beschrijving van de pressures en threats is te vinden in de meegestuurde tabel. Het is toegestaan om dezelfde factor zowel bij de pressures als bij de threats te kiezen. Er mogen maximaal vijf pressures en threats een $\mathrm{H}$ toegewezen krijgen. De pressures gaan over de rapportageperiode (2012-2017), de threats over de toekomstige periode $2019-2030$.

In de guidelines wordt de volgende toelichting gegeven (blz. 42 en 43):

\begin{tabular}{|l|l|l|}
\hline Pressure & Period of action/definition & Time-frame \\
\hline Threat & $\begin{array}{l}\text { Acting now and/or during (any part of or all } \\
\text { of) the current reporting period }\end{array}$ & Current six-year reporting period \\
\hline $\begin{array}{l}\text { Factors expected to act in the future after the } \\
\text { current reporting period }\end{array}$ & $\begin{array}{l}\text { Future two reporting periods, i.e. within } \\
12 \text { years following the end of the current } \\
\text { reporting period }\end{array}$ \\
\hline
\end{tabular}

The threats should not cover theoretical threats, but rather those issues judged to be reasonably likely. This may include continuation of pressures. Only pressures that have an important direct or immediate influence on one or several parameters of conservation status at the biogeographical scale (causing significant decline or deterioration or preventing species from reaching favourable status, see Table 6 above) should be ranked as 'high'. However, it is likely that species with Favourable conservation status or where only very localised or slight declines were recorded will not have high importance pressures (unless the pressures are counteracted with measures).

\begin{tabular}{|l|l|l|}
\hline Code & Meaning & Comment \\
\hline $\mathrm{H}$ & High importance/impact & $\begin{array}{l}\text { Important direct or immediate influence and/or acting over large areas } \\
\text { (e.g. a pressure is the major cause or one of the major causes, if acting in } \\
\text { combination with other pressures, of decline of species population, range } \\
\text { or habitat area or deterioration of habitat quality; or pressure acting over } \\
\text { large areas preventing the species population or habitat from being } \\
\text { restored at Favourable Conservation Status at the biogeographical scale) }\end{array}$ \\
\hline $\mathrm{M}$ & $\begin{array}{l}\text { Medium } \\
\text { importance/impact }\end{array}$ & $\begin{array}{l}\text { Medium direct or immediate influence, mainly indirect influence and/or } \\
\text { acting over moderate part of the area/acting only regionally (other } \\
\text { pressure not directly or immediately causing declines) }\end{array}$ \\
\hline
\end{tabular}

The impact of the pressure should reflect the influence of a pressure or threat on conservation status of the species.

\begin{tabular}{ll|l}
$\begin{array}{l}\text { 8.2 Sources of } \\
\text { information }\end{array}$ & $\begin{array}{l}\text { If available, provide sources of information (URL, metadata) } \\
\text { supporting evidence of pressures reported as 'High' }\end{array}$ \\
\hline Optional
\end{tabular}

Geef, wanneer je dat hebt, hier informatiebronnen weer die je hebt gebruikt om de drukfactoren met een hoge impact $(\mathrm{H})$ te bepalen.

\subsection{Additional information}

Optional
If you wish, give additional information on the nature of a certain pressure/threat.

Optioneel. Uit de guidelines (blz. 44):

The maximum number of 'high' ranked pressures and/or threats that can be reported is five, even if more could be considered. This, together with any other information related to pressures and threats, can be noted in field 8.3. 


\section{Conservation measures}

Alleen verplicht voor Bijlage II-soorten, maar mag ook ingevuld worden voor Bijlage IV-soorten

Uit de Guidelines (blz. 45):

This section concerns information on conservation measures, including management plans, taken to maintain or to restore the species at Favourable conservation status. The section contains a list of measures and their evaluation. The evaluation is an overall assessment and not a measure-bymeasure evaluation.

\subsection{Status of measures}

Measures are needed? (YES/NO)

If $Y E S$, continue filling in the remaining fields in this section If $N O$, do not fill in the remaining fields in this section

a) Measures identified, but none yet taken? (YES/NO)

b) Measures identified and taken? (YES/NO)

c) Measures needed but cannot be identified (YES/NO)

Geef aan of er maatregelen nodig zijn of niet (eerste vraag). Zo ja, vul dan ook de volgende vragen in. Kies optie a als de belangrijkste maatregelen al bekend maar nog niet genomen zijn, kies optie b als de belangrijkste maatregelen al geïmplementeerd zijn.

\subsection{Main purpose of the measures taken} a) Maintain the current range, population and/or habitat for the
species
b) Expand the current range of the species (related to 'Range')
c) Increase the population size and/or improve population
dynamics (improve reproduction success, reduce mortality, improve age/sex structure) (related to 'Population')
d) Restore the habitat of the species (related to 'Habitat for the species')

Vul dit veld alleen in als je bij 9.1b YES (measures identified and taken) hebt ingevuld. Geef hier aan wat het belangrijkste doel is van de genomen maatregelen. Er mag maar één antwoord gegeven worden, dus als er meerdere doelen een rol spelen, kies dan de belangrijkste.

\subsection{Location of the measures \\ a) Only inside Natura 2000 \\ b) Both inside and outside Natura 2000 \\ c) Only outside Natura 2000}

Vul dit veld alleen in als je bij 9.1b YES (measures identified and taken) hebt ingevuld. Geef hier of de maatregelen a) allemaal (of grotendeels) binnen N2000-gebieden plaatsvinden, b) proportioneel zowel binnen als buiten N2000-gebieden plaatsvinden, of c) allemaal (of grotendeels) buiten N2000-gebieden plaatsvinden.

\subsection{Response to the measures \\ a) Short-term results (within the current reporting period, 2013-2018) \\ b) Medium-term results (within the next two reporting periods, 2019- 2030) \\ c) Long-term results (after the next two reporting rounds, after 2030)}

Schat in wanneer je verwacht dat de genomen of te nemen maatregelen de 'pressures' zullen neutraliseren en een positief effect zullen veroorzaken.

\subsection{List of main conservation measures}

The list of conservation measures mirrors the list of pressures and threats, and the conservation measures are principally understood as an action to mitigate the impact of past and present pressures.

Kies hier maximaal 10 maatregelen uit de lijst. De meegeleverde lijst is tegengesteld aan de lijst van pressures and threats en de gebruikte coderingen komen overeen.

\subsection{Additional information $\quad$ Free text Optional}

Ruimte voor extra toelichting wanneer dat kan helpen om de informatie uit dit onderdeel beter te begrijpen. 


\section{Habitat for the species}

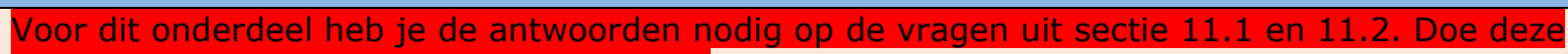

dus eerst (zie verderop in de handleiding)!

Definitie leefgebied (habitat) uit de Guidelines (blz. 39):

Habitat for the species refers to the resources necessary at all stages in the life cycle of the species, for example both wintering and summer roosts, plus foraging areas, for bats. Habitat quality includes elements like the availability of prey but also fragmentation where appropriate for the species.

\subsection{Sufficiency of area and quality of occupied habitat}

a) Are area and quality of occupied habitat sufficient (for longterm survival) YES/NO/Unknown?

b) If NO, Is there a sufficiently large area of unoccupied habitat of suitable quality (for long-term survival) YES/NO/Unknown?

Uit de Guidelines (blz. 137-141):

There are three key elements for assessing habitat for a species: area, quality and spatial organisation. The questions in field 7.1 ('Are area and quality of occupied habitat sufficient (for long-term survival)?' and 'If NO, is there a sufficiently large area of unoccupied habitat of suitable quality (for long-term survival)?' aim to identify if habitat, in its broadest sense, is the factor limiting a species from being in a Favourable conservation status by asking if the combination of habitat area and quality is sufficient.

Habitat quality should be understood as the 'ability of the environment to provide conditions appropriate for individual and population persistence'. Quality must be understood as an adequacy or suitability for the species (sometimes for a particular life stage of a species), and not as habitat condition as such without taking into account the particular requirements of the species (at its particular life stage). Habitat quality is a continuous variable and refers to resources available for survival, reproduction and population persistence.

For the generalist species it is less likely that the 'habitat area' is a limiting factor controlling the population size or reproduction than for a 'specialist' species dependent on one or a limited number of habitats (habitat types). So the assessment of the 'Sufficiency of area and quality of occupied habitat' (field 7.1(a) and (b)) should mainly focus the 'habitat quality'.

Field 7.1(b) asks if unoccupied habitat of suitable quality is available. For some species where the requirements are well known this may be relatively easy to answer. However, for many species our lack of knowledge may mean that the only response is 'unknown'.

The potential unoccupied habitat may not include all occurrences of a potential habitat within the biogeographical region, but only areas that can be recolonised by the species. If, for example, there are stretches of rivers inaccessible to the species' populations due to waterfalls or barriers, these should not be included under potential unoccupied habitat as it is unlikely that they can be recolonised by the species, even though they are of suitable quality.

Volg onderstaande beslisboom om antwoord te geven op de vragen van sectie 7.1 en beschrijf de wijze van redenatie in sectie 7.9:

a) Is 11.1 Range en 11.2 Population met FV beoordeeld?

Ja $\rightarrow$ kies YES voor 7.1a.

Nee $\rightarrow$ ga naar vraag $b$.

b) Neem nu de Pressures door die je hebt ingevuld bij sectie 8.1. Is er minstens één Pressure die erop duidt dat de oppervlakte en/of de kwaliteit van het leefgebied te klein is binnen het verspreidingsgebied van de soort (range).

$\mathrm{Ja} \rightarrow$ kies NO voor 7.1a en vul vraag 7.1b in.

Nee $\rightarrow$ ga naar vraag $c$.

c) Staat de soort genoemd in tabel 7.1 hieronder? Zo ja, dan is er een leefgebiedkaart beschikbaar. Deze kaarten geven de oppervlaktes in twee kwaliteitsklassen (alleen binnen N2000). Laat de leefgebiedkaart voldoende leefgebied van goede kwaliteit zien en in de goede configuratie (zie voor de bijbehorende getallen ook tabel 7.1)?

$\mathrm{Ja} \rightarrow$ kies YES voor 7.1a.

Nee, er zijn geen leefgebiedkaarten $\rightarrow$ ga naar vraag $d$.

Nee, niet voldoende leefgebied op de kaarten $\rightarrow$ kies NO voor $7.1 \mathrm{a}$ en vul vraag $7.1 \mathrm{~b}$ in. 
Tabel 7.1: Annex II-soorten met bezet en mogelijk bezet geschikt leefgebied in N2000-gebieden (uit: Sierdsema H., van Kleunen A., van den Bremer L., Sparrius L., Smit J., Gmelig Meyling A., Termaat T., Kranenbarg J., Hollander H., Zollinger R. \& Stahl J. 2016. Leefgebiedenkaarten van de Natura 2000-gebieden en PAS-gebieden. Sovon-rapport 2016/21. Sovon Vogelonderzoek Nederland, Nijmegen.)

\section{In km2}

Beekprik

Bittervoorn

Blauwe Kiekendief

Dodaars

Donker

pimpernelblauwtje

Drijvende

waterweegbree

Geel schorpioenmos

Gevlekte witsnuitlibel

Grote vuurvlinder

Kamsalamander

Kruipend moerasscherm

Nauwe korfslak

Pimpernelblauwtje

Platte schijfhoren

Zeggekorfslak

\begin{tabular}{|c|}
\hline $\begin{array}{c}\text { Bezet } \\
\text { geschikt } \\
\text { leefgebied }\end{array}$ \\
\hline 0,45 \\
\hline 8,61 \\
\hline 5,70 \\
\hline 3,72 \\
\hline 0,05 \\
\hline 0,18 \\
\hline 0,02 \\
\hline 7,41 \\
\hline 1,92 \\
\hline 2,23 \\
\hline 0,10 \\
\hline 31,75 \\
\hline 0,55 \\
\hline $\begin{array}{c}8,21 \\
32,33\end{array}$ \\
\hline
\end{tabular}

\section{Mogelijk bezet}

geschikt

leefgebied

0,54

13,11

1,58

0,24

1,70

1,40

0,28

6,14

1,36

4,12

0,24

97,65

1,09

7,99

11,51

Eindtotaal
0,98
21,72
7,28
3,97
1,75
1,58
0,29
13,55
3,29
6,35
0,33
129,41
1,64
16,20
43,84

d) Voor niet-stikstofgevoelige Annex II soorten alsmede voor soorten met een belangrijk deel van hun verspreiding buiten Natura 2000 gebieden: zijn er andere bronnen (bijv.

kansenkaarten)? Beoordeel deze met expert judgement: laten ze voldoende leefgebied van goede kwaliteit zien en in de goede configuratie?

Ja $\rightarrow$ kies YES voor 7.1a.

Nee, er zijn geen andere bronnen $\rightarrow$ ga naar vraag e.

Nee, niet voldoende leefgebied $\rightarrow$ kies NO voor $7.1 \mathrm{a}$ en vul vraag $7.1 \mathrm{~b}$ in.

e) Beoordeel de soort op basis van expert judgement. Is er voldoende leefgebied van goede kwaliteit en in de juiste configuratie aanwezig voor overleving van de soort op de lange termijn? Je kunt als hulpmiddel ook nog de extra beslisboom op de volgende bladzijde gebruiken.

$\mathrm{Ja} \rightarrow$ kies YES voor 7.1a.

Nee $\rightarrow$ kies NO voor 7.1a en vul vraag 7.1b in.

Geen idee $\rightarrow$ kies UNKNOWN voor 7.1a.

\subsection{Sufficiency of area and quality of occupied habitat Method used}

Select one of the following methods:

a) Complete survey or a statistically robust estimate

b) Based mainly on extrapolation from a limited amount of data

c) Based mainly on expert opinion with very limited data

d) Insufficient or no data available

Indien leefgebiedkaarten or kansenkaarten voorhanden zijn, kies dan voor a. Anders b, c of zelfs $d$, afhankelijk van de hoeveelheid data en naar inschatting van de expert.

\subsection{Short-term trend} Period 2007-2018 (rolling 12-year time window) or period as close as possible to it. The short-term trend should be used for the

2006-2017. assessment of habitat for species 


\subsection{Short-term trend}

\section{Direction}

Net als de vorige keer wordt de korte termijn-trend samengesteld uit de trends voor oppervlakte en kwaliteit. En net als toen is er, wellicht met uitzondering van enkele goed onderzochte soorten, geen informatie beschikbaar over de trend in oppervlakte en kwaliteit. Wanneer er geen informatie beschikbaar is, schat dan zowel oppervlakte als kwaliteit eerst apart in (in de categorieën decreasing, stable, increasing, uncertain of unknown) over de periode 2006-2017. Daarna moeten ze worden gecombineerd via onderstaande tabel:

\begin{tabular}{|l|l|}
\hline Reported trend & Relation to area/quality status \\
\hline stable & Both trends are stable \\
\hline increasing & One or both trends are increasing or stable \\
\hline One or both trends are decreasing \\
\hline decreasing & $\begin{array}{l}\text { At least one trend is unknown and non- } \\
\text { decreasing or there is no dominating trend }\end{array}$ \\
\hline Unknown / uncertain & $\begin{array}{l}\text { Select one of the following methods: } \\
\text { Method used }\end{array}$ \\
& $\begin{array}{l}\text { a) Complete survey or a statistically robust estimate } \\
\text { b) Based mainly on extrapolation from a limited amount of data } \\
\text { c) Based mainly on expert opinion with very limited data } \\
\text { d) Insufficient or no data available }\end{array}$ \\
\hline
\end{tabular}

Al hebben we voor een aantal soorten informatie over de oppervlakte, voor zover bekend is er nergens data over de trend in oppervlakte en kwaliteit (wellicht m.u.v. enkele goed onderzochte soorten). Dit zal daarom af en toe met b), maar vaak met c) worden ingevuld (en heel soms met d).

\begin{tabular}{|c|c|}
$\begin{array}{l}\text { 7.6 - 7.8 Long-term } \\
\text { trend }\end{array}$ & A trend calculated over 24 years (1994-2018) \\
Optional & \\
\hline
\end{tabular}

Optioneel, niet invullen.

\begin{tabular}{rl|l}
\hline 7.9 Additional information & $\begin{array}{l}\text { Other relevant information, complementary to the data } \\
\text { requested under fields } 7.1-7.8 \\
\text { Free text }\end{array}$ \\
Optional
\end{tabular}

Geef hier nauwkeurig weer hoe je tot de antwoorden bij 7.1 en 7.2 bent gekomen, en verder mag je hier extra informatie kwijt die je nodig acht om de informatie uit deze sectie beter te begrijpen. 


\section{Future prospects}

Uit de Guidelines (blz. 47):

Future prospects indicate the direction of expected change in conservation status in the near future based on a consideration of the current status, reported pressures and threats, and measures being taken for each of the other three parameters (Range, Population and Habitat of the species). Future prospects of each of the three parameters should principally reflect the future trends which are the result of the balance between threats and conservation measures. The future prospects should be assessed in relation to the current conservation status.

'Future prospects' should be evaluated by individually assessing the expected future trends and subsequently future prospects of each of the other three parameters, taking primarily into account the current conservation status of the parameter, threats (related to the parameter assessed) and the conservation measures being taken or planned for the future. The assessment can be divided into 3 steps:

1. Future trends of parameters;

2. Future prospects of parameters;

3. Assessing overall Future prospects for a species.

\begin{tabular}{|l|l|l|}
\hline $\begin{array}{l}\text { 10.1 Future prospects of } \\
\text { parameters }\end{array}$ & a) Range & Good / Poor / Bad / Unknown \\
\cline { 2 - 3 } & b) Population & Good / Poor / Bad / Unknown \\
\cline { 2 - 3 } & c) Habitat of the species & Good / Poor / Bad / Unknown \\
\hline
\end{tabular}

Geef voor elke parameter aan wat het toekomstperspectief is. De 'toekomst' is in principe de periode van de volgende twee rapportages, dus 2019-2030. Er is echter flexibiliteit mogelijk, bijvoorbeeld in het geval van dieren met een lange generatietijd, of wanneer gevolgen van klimaatverandering op een soort al over een langere tijdspanne bekend zijn. Volg voor het bepalen van het toekomstperspectief per parameter onderstaand stappenplan (Guidelines, blz. 144-148):

\section{Step 1 Future trends of parameters ( $1^{\mathrm{e}}$ en $2^{\mathrm{e}}$ kolom van onderstaande tabel)}

Future trends of a species are dependent on the identified (known and likely) threats which will have a negative impact, and any action plans, conservation measures and other provisions which will have a positive impact. The measures should be restricted to those anticipated to have a positive impact in the next 12 years (regardless of whether they were already being implemented during the current reporting period or not). The assessment of future trends has to take into account whether the sum of positive and negative influences (threats) will balance out for the parameter under consideration, or whether either the positive or negative effects are likely to be stronger. In some cases threats or measures may affect the three parameters differently. Only threats and conservation measures related to the specific parameter should be considered.

Establishing whether the future trend is negative or very negative (or positive/very positive) will be difficult in most cases, although it may be easier if the current trend and trend magnitude are known or in cases of dominating pressures or measures. To differentiate between negative and very negative (and positive or very positive) trends the threshold of $1 \%$ per year, meaning approximately $12 \%$ in 12 years, is recommended. 
Step 2 Future prospects of parameters (combineer de 2 e en 3e kolom van de tabel en bepaal de juiste conclusie in de 4 e kolom van de tabel)

The future prospects of a parameter are assessed by taking into consideration, principally, the future trends and current conservation status. Deciding between the two options proposed for each combination of future trends and current conservation status will mainly depend on the potential trend magnitude (negative/very negative or positive/very positive). This is a pragmatic and mechanistic approach aimed at simplifying and harmonising the assessment of Future prospects.

\begin{tabular}{|c|c|c|c|c|}
\hline Threats and measures & $\begin{array}{l}\text { Predicted Future } \\
\text { Trend reflects } \\
\text { balance between } \\
\text { threats and } \\
\text { measures }\end{array}$ & $\begin{array}{l}\text { Current } \\
\text { Conservation } \\
\text { status of } \\
\text { parameter }\end{array}$ & \multicolumn{2}{|c|}{$\begin{array}{l}\text { Future Prospects of } \\
\text { parameter } \\
\text { (over next } 12 \text { years) }\end{array}$} \\
\hline \multirow{4}{*}{$\begin{array}{l}\text { Balance between threats acting } \\
\text { on the parameter (mostly threats } \\
\text { with insignificant impact and/or } \\
\text { Medium impact threats) and } \\
\text { conservation measures; no real } \\
\text { change in status of the parameter } \\
\text { expected }\end{array}$} & \multirow[t]{4}{*}{ overall stable $=$} & FV & \multicolumn{2}{|l|}{ good } \\
\hline & & U1 & \multicolumn{2}{|l|}{ poor } \\
\hline & & U2 & \multicolumn{2}{|l|}{ Bad } \\
\hline & & $x X$ & \multicolumn{2}{|l|}{ Unknown } \\
\hline \multirow{4}{*}{$\begin{array}{l}\text { Threats expected to have } \\
\text { negative influence on the status } \\
\text { of the parameter (mostly High or } \\
\text { Medium impact threats), } \\
\text { irrespective of measures taken }\end{array}$} & \multirow[t]{4}{*}{$\begin{array}{l}\text { negative - / very } \\
\text { negative -- }\end{array}$} & FV & poor (-) & bad (--) \\
\hline & & U1 & poor (-) & bad (--) \\
\hline & & $\mathrm{U2}$ & bad & \\
\hline & & $X X$ & poor (-) & bad (--) \\
\hline \multirow{4}{*}{$\begin{array}{l}\text { None (or only threats with } \\
\text { insignificant impact) and/or } \\
\text { effective measures taken: } \\
\text { positive influence on the status of } \\
\text { the parameter expected }\end{array}$} & \multirow[t]{4}{*}{$\begin{array}{l}\text { positive + / very } \\
\text { positive }++\end{array}$} & $\mathrm{FV}$ & \multicolumn{2}{|l|}{ good } \\
\hline & & U1 & Poor $(+)$ & Good $(++)$ \\
\hline & & U2 & Poor $(+)$ & Good $(++)$ \\
\hline & & $x x$ & Poor $(+)$ & Good $(++)$ \\
\hline \multirow{4}{*}{$\begin{array}{l}\text { Threats and/or measures taken } \\
\text { unknown or interaction not } \\
\text { possible to predict }\end{array}$} & \multirow[t]{4}{*}{ unknown } & $\mathrm{FV}$ & \multirow{4}{*}{\multicolumn{2}{|c|}{ unknown }} \\
\hline & & U1 & & \\
\hline & & U2 & & \\
\hline & & $X X$ & & \\
\hline
\end{tabular}

\section{Step 3 Assessing overall Future prospects for a species}

Once the future prospects of each of the other three parameters have been evaluated, they should be combined to give the overall assessment of 'Future prospects' using the rules in this table:

\begin{tabular}{|l|l|l|l|l|}
\hline & Favourable & $\begin{array}{l}\text { Unfavourable- } \\
\text { Inadequate }\end{array}$ & Unfavourable-Bad & Unknown \\
\hline $\begin{array}{l}\text { Future } \\
\text { prospects }\end{array}$ & $\begin{array}{l}\text { All parameters have good } \\
\text { prospects } \\
\text { OR } \\
\text { prospects of one } \\
\text { parameter unknown, the } \\
\text { other prospects good }\end{array}$ & Other combination & $\begin{array}{l}\text { One or more } \\
\text { parameters have bad } \\
\text { prospects }\end{array}$ & $\begin{array}{l}\text { Two } \\
\text { or more x } \\
\text { and no } \\
\text { parameter } \\
\text { with bad } \\
\text { prospects }\end{array}$ \\
\hline
\end{tabular}

De uitkomst van stap 3 wordt pas ingevuld bij sectie 11.4 .

\subsection{Additional information $\quad$ Free text Optional}

Ruimte voor extra toelichting wanneer dat kan helpen om de informatie uit dit onderdeel beter te begrijpen (bv. om bij een volgende ronde te kunnen begrijpen wat je hier ook al weer bedoelde (-)). 


\section{Conclusions}

Gebruik voor het bepalen van de Conservation Status de bijgeleverde Annex C. Als het goed gaat, en je hebt alle velden goed ingevuld, zal de conclusie automatisch worden getrokken. Mocht dat niet gebeuren, volg dan het onderstaande stuk.

\subsection{Range} Favourable (FV) / Inadequate (U1) / Bad (U2) / Unknown (XX)

Gebruik als 'short-term trend' voor de Range de waarde die je hebt ingevuld bij sectie 5.3. Gebruik verder wat je hebt ingevuld bij 5.1 (range surface area) en bij 5.10 (favourable reference range).

De status of Range mag niet uitkomen op Favourable wanneer er sprake is van veranderingen op grote schaal die veroorzaakt worden door menselijke drukfactoren, maar die geen invloed hebben op de oppervlakte van de range (bijvoorbeeld wanneer de grenzen van de range verschuiven, maar het oppervlak vooralsnog gelijk blijft).

\begin{tabular}{l|l} 
11.2 Population & Favourable (FV) / Inadequate (U1) / Bad (U2) / Unknown (XX)
\end{tabular}

Gebruik de waarden die je hebt ingevuld bij 6.2 of 6.4 (population size), 6.15 (favourable reference population) en 6.8 (short-term trend).

11.3 Habitat for the species Favourable (FV) / Inadequate (U1) / Bad (U2) / Unknown (XX)

Gebruik hiervoor wat je hebt ingevuld bij sectie 7.1 en 7.4.

Wanneer je bij één van de vragen in 7.1 YES hebt ingevuld, is het waarschijnlijk dat je hier voor Favourable kiest.

\begin{tabular}{|l|l}
\hline 11.4 Future prospects & Favourable (FV) / Inadequate (U1)/ Bad (U2) / Unknown (XX)
\end{tabular}

Vul hier de uitkomst van stap 3 uit sectie 10.1 in.

$\mathbf{1 1 . 5}$ Overall assessment of Conservation Status

Favourable (FV) / Inadequate (U1) / Bad (U2) / Unknown (XX)

Gebruik de onderste regel uit de tabel in Annex $\mathrm{C}$ om te bepalen wat de uitkomst is van de 'overall conservation status'.

\begin{tabular}{l|l}
$\begin{array}{l}11.6 \text { Overall trend in } \\
\text { Conservation Status }\end{array}$ & $\begin{array}{l}\text { Use qualifier ' }+ \text { ' (improving), '-' (deteriorating), '=' (stable) or ' } x \text { ' } \\
\text { (unknown) for } F V, U 1 \text { and U2 }\end{array}$ \\
\hline
\end{tabular}
Vul deze vraag niet in als je bij 11.5 UNKNOWN hebt geantwoord.

Neem voor deze bepaling de trends uit sectie 5.3 (range), 6.8 (population) en 7.4 (habitat). Tel hoeveel daarvan increasing, stable, decreasing en unknown zijn en bepaal vervolgens de overall trend volgens de tabel op de volgende bladzijde. 


\begin{tabular}{|c|c|c|c|c|}
\hline \multicolumn{4}{|c|}{$\begin{array}{l}\text { Short-term| trend of parameters (Range, Population, } \\
\text { Habitat for the species }\end{array}$} & \multirow[t]{2}{*}{ Overall trend in CS } \\
\hline $\begin{array}{c}\text { Number } \\
\text { increasing }\end{array}$ & $\begin{array}{c}\text { Number } \\
\text { stable }\end{array}$ & $\begin{array}{c}\text { Number } \\
\text { decreasing }\end{array}$ & $\begin{array}{c}\text { Number } \\
\text { unknown }\end{array}$ & \\
\hline 3 & 0 & 0 & 0 & \multirow{3}{*}{$\begin{array}{c}\text { Improving } \\
\text { (Only increasing and stable trends) }\end{array}$} \\
\hline 2 & 1 & 0 & 0 & \\
\hline 1 & 2 & 0 & 0 & \\
\hline 0 & 3 & 0 & 0 & \multirow{6}{*}{$\begin{array}{l}\text { (Only stable trends or stable and increasing } \\
\text { dominates (there is at least one increasing and } \\
\text { only one unknown or decreasing)). } \\
\text { * Trend magnitude should also be considered. } \\
\text { The overall trend in CS is stable only in case of } \\
\text { moderate declines (<1\% per year). }\end{array}$} \\
\hline 2 & 0 & 1 & 0 & \\
\hline 2 & 0 & 0 & 1 & \\
\hline 1 & 1 & $1^{*}$ & 0 & \\
\hline 1 & 1 & 0 & 1 & \\
\hline & & & & \\
\hline 0 & 0 & 3 & 0 & \multirow{6}{*}{$\begin{array}{l}\text { Deteriorating } \\
\text { (Decreasing trends dominate) } \\
{ }^{*} \text { Trend magnitude should also be considered. } \\
\text { The overall trend in CS is declining only in case } \\
\text { of important declines (>1\% per year). }\end{array}$} \\
\hline 1 & 0 & 2 & 0 & \\
\hline 0 & 1 & 2 & 0 & \\
\hline 0 & 0 & 2 & 1 & \\
\hline 0 & 2 & 1 & 0 & \\
\hline 1 & 1 & $1^{*}$ & 0 & \\
\hline 0 & 0 & 0 & 3 & \multirow{6}{*}{$\begin{array}{c}\text { Unknown } \\
\text { (Unknown trends dominate) }\end{array}$} \\
\hline 1 & 0 & 0 & 2 & \\
\hline 0 & 1 & 0 & 2 & \\
\hline 0 & 0 & 1 & 2 & \\
\hline 1 & 0 & 1 & 1 & \\
\hline 0 & 1 & 1 & 1 & \\
\hline
\end{tabular}

Note: 'unknown' in the table above includes both 'unknown' and 'uncertain'.

\subsection{Change and reasons for change in conservation status and conservation status trend}

\begin{tabular}{|c|c|c|}
\hline & $\begin{array}{l}\text { Overall } \\
\text { assessment } \\
\text { of } \\
\text { conservation } \\
\text { status (11.5) }\end{array}$ & $\begin{array}{l}\text { Overall trend } \\
\text { in } \\
\text { conservation } \\
\text { status (11.6) }\end{array}$ \\
\hline $\begin{array}{l}\text { a) Are there differences between } \\
\text { reported values compared to the } \\
\text { previous reporting period? } \\
\text { If YES, select one or several of } \\
\text { the following options } b), c), \text { d) or } \\
\text { e) }\end{array}$ & YES/NO & YES/NO \\
\hline b) Genuine change & YES/NO & YES/NO \\
\hline $\begin{array}{l}\text { c) More accurate data or } \\
\text { improved knowledge }\end{array}$ & $Y E S / N O$ & YES/NO \\
\hline $\begin{array}{l}\text { d) Use of different methods } \\
\text { (including taxonomical change or } \\
\text { use of different thresholds) }\end{array}$ & YES/NO & YES/NO \\
\hline $\begin{array}{l}\text { e) No information on nature of } \\
\text { change }\end{array}$ & $Y E S / N O$ & YES/NO \\
\hline $\begin{array}{l}\text { f) Which of } b), c) \text {, or } d \text { ) is the } \\
\text { main reason for change? }\end{array}$ & $\begin{array}{l}\text { Report b), c) } \\
\text { ord) }\end{array}$ & $\begin{array}{l}\text { Report b), c) } \\
\text { or d) }\end{array}$ \\
\hline \multicolumn{3}{|c|}{$\begin{array}{l}\text { de antwoorden bij } 11.5 \text { en } 11.6 \text { verschillen met de vorige } \\
\text { is, wat dan de aard is van de verandering. Beantwoord eerst de } \\
\text { twoordt, beantwoord dan ook de rest van de vragen. Er kunnen } \\
\text { worden, geef dan bij f aan wat de belangrijkste reden van de }\end{array}$} \\
\hline \multicolumn{3}{|l|}{ Free text } \\
\hline
\end{tabular}




\begin{tabular}{|c|c|c|}
\hline \multirow{4}{*}{$\begin{array}{l}\text { 12.1 Population size inside } \\
\text { the pSCIs, SCIs and SACs } \\
\text { network } \\
\text { (on the biogeographical/ } \\
\text { marine level) }\end{array}$} & a) Unit & Use agreed unit as defined in field 6.2 a) \\
\hline & b) Minimum & $\begin{array}{l}\text { Number (raw, i.e. not rounded). Provide at } \\
\text { least one of interval }(b, c) \text { or best estimate } \\
\text { (d). If a precise value is known provide the } \\
\text { same value under both minimum and } \\
\text { maximum }\end{array}$ \\
\hline & c) Maximum & $\begin{array}{l}\text { Number (raw, i.e. not rounded). Provide at } \\
\text { least one of interval }(b, c) \text { or best estimate } \\
\text { (d). If a precise value is known provide the } \\
\text { same value under both minimum and } \\
\text { maximum }\end{array}$ \\
\hline & d) Best estimate & $\begin{array}{l}\text { Number (raw, i.e. not rounded). Provide at } \\
\text { least one of interval }(b, c) \text { or best estimate } \\
\text { (d) }\end{array}$ \\
\hline
\end{tabular}

Indien bij de soort nodig, en beschikbaar, is hier al het aantal $1 \mathrm{~km}$ gridcellen binnen de Natura 2000 gebieden ingevuld.

Gebruik anders hier dezelfde methode als bij 6.2, maar dan alleen voor de populatie binnen de grenzen van N2000-gebieden. Alles telt mee, ook wanneer de soort zich maar een deel van het jaar ophoudt in het N2000-gebied, of wanneer het N2000-gebied alleen in een bepaald levensstadium wordt gebruikt.

\section{\begin{tabular}{l|l} 
12.2 Type of estimate & Best estimate / 6-year mean / 95\% CI range / minimum
\end{tabular}}

Kies de methode die het best van toepassing is op de methode uit 12.1 (uit de guidelines, blz. 35). Als de data vooringevuld uit de NDFF komt, moet je 'Best estimate' kiezen, tenzij je goede redenen hebt om daarvan af te wijken (maar die moet je dan toelichten in 12.6).

- best estimate: the best available single figure (including where only the maximum value of the population size is available) or interval, derived from e.g. a population census, a compilation of figures from localities, modelled population size based on population densities and distribution data or expert opinion, but for which $95 \%$ confidence interval could not be calculated. Whether a best estimate comes from the monitoring data, modelling or an expert opinion should be entered in field 6.6;

multi-year mean: average value or interval where population size is monitored several times during the period provided in field 6.1;

95 \% confidence interval: estimates derived from sample surveys or a model in which $95 \%$ confidence limits could be calculated;

minimum: where insufficient data exist to provide even a loosely bounded estimate, but where a population size is known to be above a certain value, or where the reported interval estimates come from a sample survey or monitoring project which probably underestimates the real population size.

12.3 Method used Population size
$3=$ Complete survey or a statistically robust estimate, $2=$ Based mainly on extrapolation from a limited amount of data, $1=$ Based mainly on expert opinion with very limited data, $0=$ Insufficient or no data available

Kies de optie die het best beschrijft welke methode is gebruikt om de populatiegrootte uit 12.1 te berekenen. Wanneer de gebruikte data uit verschillende bronnen komt, kies dan de methode die past bij de belangrijkste en meest betrouwbare data. Als de data vooringevuld uit de NDFF komt, kun je meestal 3 kiezen.

12.4 Short-term trend of population size within the network - direction
Short-term trend of population size within the network over the period indicated in field 6.5 is:

$0=$ stable $/+=$ increasing $/-=$ decreasing $/ u=$ uncertain $/ x=$ unknown 
Voor sommige soorten met NEM-populatietrends of occupancytrends is dit direct berekend en al ingevuld.

Waar dat niet mogelijk is, en volwassen individuen de eenheid zijn, kan een vergelijking met een vorige rapportage gemaakt worden via Chi-kwadraat. Anders zal het vooral op je expert oordeel aankomen.

De trendperiode waar het om gaat is 2006-2017.

\subsection{Method used}

Trend direction

$3=$ Complete survey or a statistically robust estimate, $2=$ Based mainly on extrapolation from a limited amount of data, $1=$ Based mainly on expert opinion with very limited data, $0=$ Insufficient or no data available

Kies de optie die het best beschrijft welke methode is gebruikt om de trend uit 12.4 te berekenen. Als NEM populatietrends of occupancytrends gebruikt zijn, kun je hier een 3 kiezen.

Wanneer de gebruikte data uit verschillende bronnen komt, kies dan de methode die past bij de belangrijkste en meest betrouwbare data.

\begin{tabular}{|l|l|}
$\begin{array}{l}\text { 12.6 Additional } \\
\text { information }\end{array}$ & Free text \\
\hline Optional & \\
\hline
\end{tabular}

Ruimte voor extra toelichting wanneer dat kan helpen om de informatie uit dit onderdeel beter te begrijpen.

\section{Complementary information}

13.1 Justification of $\%$ thresholds for trends

Optional

In case a MS is not using the indicative value of $1 \%$ per year in the assessment matrix when assessing trends, this should be duly justified in this free text field

Alleen invullen als je bij sectie 11 een andere drempelwaarde hebt gebruikt dan de gegeven $1 \%$.
13.2 Trans-boundary assessment

\section{Optional}

Where two or more MS have made a joint conservation status assessment for a trans-boundary population of a (usually wideranging) species, this should be explained here. Note clearly the Member States involved, how the assessment was carried out and any joint initiatives taken to ensure a common management of the species (e.g. population management plan)

Niet van toepassing.

\subsection{Other relevant} information

Free text

\section{Optional}

Hier kun je alle informatie kwijt die je nog kwijt wilt, maar nergens eerder kwijt hebt gekund. 
146 Arets, E.J.M.M., J.W.H van der Kolk, G.M. Hengeveld, J.P. Lesschen, H. Kramer, P.J. Kuikman \& M.J. Schelhaas (2019). Greenhouse gas reporting of the LULUCF sector in the Netherlands. Methodological background, update 2019.

147 Bruggen, C. van, A. Bannink, C.M. Groenestein, J.F.M. Huijsmans, L.A. Lagerwerf, H.H. Luesink, S.M. van der Sluis, G.L. Velthof \& J. Vonk (2019). Emissies naar lucht uit de landbouw in 2017. Berekeningen met het model NEMA.

148 Lagerwerf, L.A., A. Bannink, C. van Bruggen, C.M. Groenestein, J.F.M. Huijsmans, J.W.H. van der Kolk, H.H. Luesink, S.M. van der Sluis, G.L. Velthof \& J. Vonk (2019). Methodology for estimating emissions from agriculture in the Netherlands. Calculations of $\mathrm{CH} 4, \mathrm{NH} 3, \mathrm{~N} 2 \mathrm{O}$, NOX, NMVOC, PM10, PM2.5 and CO2 with the National Emission Model for Agriculture (NEMA) - update 2019.

149 Bakker, G., M. Heinen, H.P.A. Gooren, W.J.M. de Groot, F.B.T. Assinck \& E.W.J. Hummelink (2019). Hydrofysische gegevens van de bodem in de Basisregistratie Ondergrond (BRO) en het Bodemkundig Informatie Systeem (BIS); Update 2018.

150 IJsseldijk, L.L., M.J.L. Kik, \& A. Gröne (2019). Postmortaal onderzoek van bruinvissen (Phocoena phocoena) uit Nederlandse wateren, 2018. Biologische gegevens, gezondheidsstatus en doodsoorzaken.

151 Daamen, W.P., A.P.P.M. Clerkx \& M.J. Schelhaas (2019). Veldinstructie Zevende Nederlandse Bosinventarisatie (2017-2021); Versie 2.0.

152 Bikker, P., L.B. Šebek, C. van Bruggen \& O. Oenema (2019). Stikstof- en fosfaatexcretie van gangbaar en biologisch gehouden landbouwhuisdieren. Herziening excretieforfaits Meststoffenwet 2019.

153 Berg, F. van den, H. Baveco \& E.L. Wipfler (2019). User manual for SAFE (Select Application date For Evaluation) to support the use of the GEM scenarios for cultivations in glasshouses; Version 1.1

154 Os, J. van, L.J.J. Jeurissen en H.H. Ellen (2019). Rekenregels pluimvee voor de Landbouwtelling; Verantwoording van het gebruik van het Identificatie- \& Registratiesysteem.

155 Brouwer, F. \& D.J.J. Walvoort (2019). Basisregistratie Ondergrond (BRO) Actualisatie bodemkaart; Herkartering van de veengebieden in Eemland

156 Sanders, M.E., R.J.H.G. Henkens \& D.M.E. Slijkerman (2019). Convention on Biological
Diversity; Sixth National Report of the Kingdom of the Netherlands.

157 Kuiters, A.T., G.A. de Groot, D.R. Lammertsma, H.A.H. Jansman, J. Bovenschen, M.C. Boerwinkel \& M. Laar (2019). Genetische monitoring van de Nederlandse otterpopulatie; Ontwikkeling van populatieomvang en genetische status 2018/2019.

158 Sanders, M.E. \& H.A.M. Meeuwsen (2019). Basisbestand Natuur en Landschap.

159 Visser, T., H.A.M Meeuwsen \& Th.C.P. Melman (2019). MNP-(Model for Nature Policy) Agrarisch; Uitwerking voor scenario's uit de Natuurverkenning 2020.

160 Jong, A. de, A. Poot \& P.I. Adriaanse (2019). Impact analysis for the purpose of the introduction of DROPLET version 1.3.2.

161 Westerink, J., T.A. de Boer, M. Pleijte \& R.A.M. Schrijver (2019). Kan een goede boer natuurinclusief zijn?; De rol van culturele normen in een beweging richting natuurinclusieve landbouw.

162 Buijs, A.E., F.G. Boonstra (2020). Natuurbeleid betwist; Visies op legitimiteit en natuurbeleid.

163 Haas, W. de, J.L.M. Donders, T.J.M. Mattijssen (2019). Natuur in conflict; Botsende waarden, waarheden en belangen in het natuurbeheer.

164 Berg, F. van den, A. Tiktak, D. van Kraalingen \& J.J.T.I. Boesten (2019). User manual for FOCUSPEARL version 5.5.5.

165 Glorius, S.T., A. Meijboom, J. Schop \& J.T. van der Wal (2019). Ontwikkeling van enkele droogvallende mosselbanken in de Nederlandse Waddenzee; situatie 2018.

166 Pedroli, B, During, R. (2019). De paradox van een maakbare natuur - ingebakken en omstreden; Betekenis culturele identiteit voor draagvlak natuurbeleid en -beheer.

167 Walvoort, D.J.J., M. Knotters, F.M. van Egmond (2019). Interpolatie, aggregatie en desaggregatie van ruimtelijke bodemgegevens in de Basisregistratie Ondergrond (BRO).

168 Arets, E.J.M.M., J.W.H van der Kolk, G.M. Hengeveld, J.P. Lesschen, H. Kramer, P.J. Kuikman \& M.J. Schelhaas (2020). Greenhouse gas reporting of the LULUCF sector in the Netherlands. Methodological background, update 2020.

170 Bos-Groenendijk, G.I., C.A.M van Swaay (2020). Habitatrichtlijnrapportage 2019: Annex B Habitatrichtlijnsoorten; Achtergronddocument. 


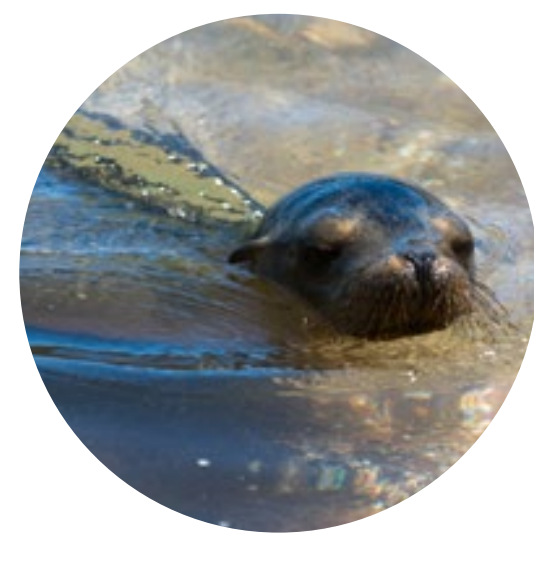

Thema Informatievoorziening Natuur Wettelijke Onderzoekstaken Natuur \& Milieu

Postbus 47

6700 AA Wageningen

T (0317) 485471

E info.wnm@wur.nl

ISSN 2352-2739

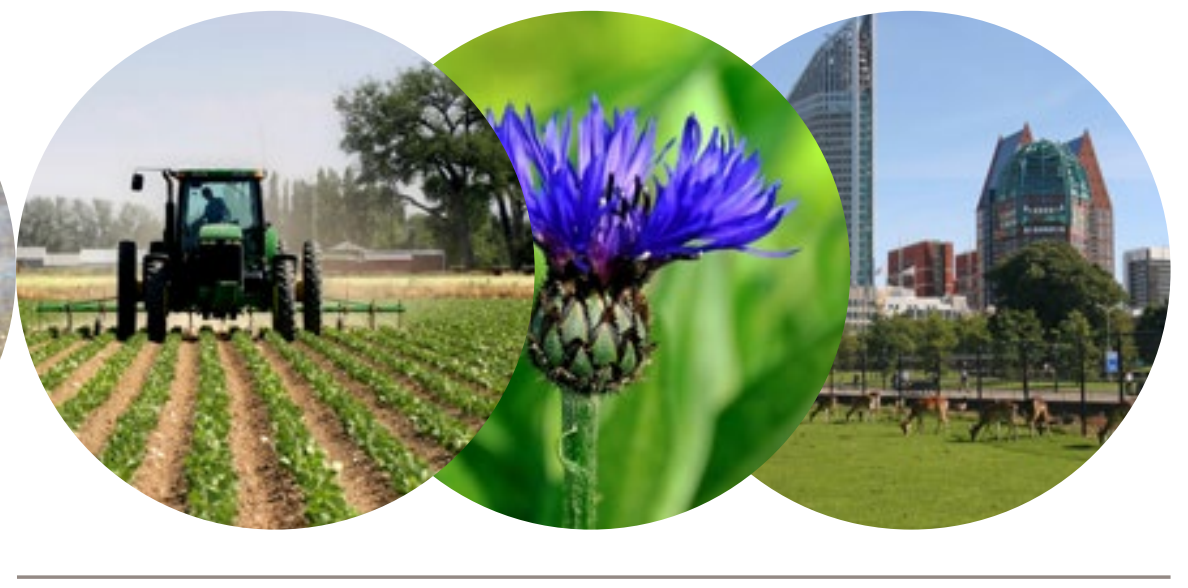

De missie van Wageningen University \& Research is 'To explore the potential of nature to improve the quality of life'. Binnen Wageningen University \& Research bundelen 9 gespecialiseerde onderzoeksinstituten van Stichting Wageningen Research en Wageningen University hun krachten om bij te dragen aan de oplossing van belangrijke vragen in het domein van gezonde voeding en leefomgeving. Met ongeveer 30 vestigingen, 5.000 medewerkers en 10.000 studenten behoort Wageningen University \& Research wereldwijd tot de aansprekende kennisinstellingen binnen haar domein. De integrale benadering van de vraagstukken en de samenwerking tussen verschillende disciplines vormen het hart van de unieke Wageningen aanpak. 